\title{
Fragmentación vs. integración comunal: Repensando el Período Tardío del Noroeste Argentino
}

FÉLIX A. ACUTO ${ }^{1}$

\section{RESUMEN}

\begin{abstract}
El Período Tardío del Noroeste Argentino ha sido caracterizado como una época de creciente complejidad, desigualdad social y estratificación político-económica institucionalizadas. El objetivo de este artículo es discutir críticamente esta interpretación y la evidencia empleada para apoyarla. Sostengo que si abandonamos las perspectivas externas y a "vuelo de pájaro" al analizar los poblados de esta época y si nos enfocamos en las experiencias subjetivas e intersubjetivas, las prácticas y las relaciones sociales que se desarrollaban diariamente en estos lugares, entonces alcanzaremos una visión distinta de las sociedades tardías, las cuales, argumento, desarrollaron una vida social más cercana a la integración comunal que a la estratificación y segregación.
\end{abstract}

Palabras claves: Período Tardío - poblados conglomerados experiencias - relaciones sociales - integración comunal.

\begin{abstract}
Northwest Argentina's Late Pre-Hispanic Period has been generally characterized as a time of increasing complexity, institutionalized social inequality and political-economic stratification. This article's goal is to critically discuss this view and the evidence employed to support it. I claim that if we leave aside "bird's-eye" views when analyzing late-period sites and focus instead on the subjective and intersubjective experiences, practices, and social relations that past people daily developed in these places, we will then be able to reach a different understanding of late-period societies, which, I argue, developed a social life that was closer to communal integration than to stratification and segregation.
\end{abstract}

Key words: Late Period - conglomerated settlements - experiences - social relations - communal integration.

Recibido: diciembre 2006. Aceptado: junio 2007.

\section{Introducción}

El Período Tardío (1000-1450 DC) $)^{2}$ del Noroeste Argentino ha sido generalmente caracterizado como una época de desarrollos regionales, conflictos interregionales, complejidad sociopolítica, desigualdad social y estratificación económica institucionalizadas (Núñez Regueiro 1974; Ottonello y Lorandi 1987; Tarragó 2000; Nielsen 2001). Se ha sostenido que durante esta época, unidades políticas tipo jefaturas habrían ejercido su poder sobre territorios específicos, al mismo tiempo que surgían los primeros asentamientos extensos y conglomerados, considerados cabeceras de gobierno y administración de un sistema político estratificado (Figura 1). De acuerdo a esto, el camino hacia la complejidad social, la desigualdad y la estratificación, iniciado al menos en algunas regiones del Noroeste Argentino (en adelante N.O.A.), durante el Período Medio con Aguada, parecería haberse acentuado y consolidado durante el Período Tardío.

En la arqueología del N.O.A. ha sido frecuente el empleo, ya sea implícita o explícitamente, de los modelos sobre evolución social propuestos en la década de 1960 (Fried 1967; Service 1984), que establecen una sucesión lineal de tipos de sociedades u organizaciones políticas, que va de menor a mayor complejidad, especialmente en los aspectos políticos y económicos. Así, un período de complejidad sociopolítica emergente es siempre seguido por otro de mayor complejidad, estratificación y desigualdad. Cada uno de estos tipos de sociedades cuenta con una estructura política (representada por niveles de toma de decisiones), una organización económica y modo de producción, un nivel de desarrollo tecnológico, una forma de ocupar el espacio, entre otros, que les son propios. Se plantearon ciertas expectativas de registro para cada caso (banda. tribu, jefatura o Estado), especialmente expresadas en patrón de asentamiento, infraestructura de producción

\footnotetext{
2 Período inmediatamente anterior a la expansión incaica. Coincide con el Período Intermedio Tardío para los Andes Centrales, Centro-Sur y Chile.
} 


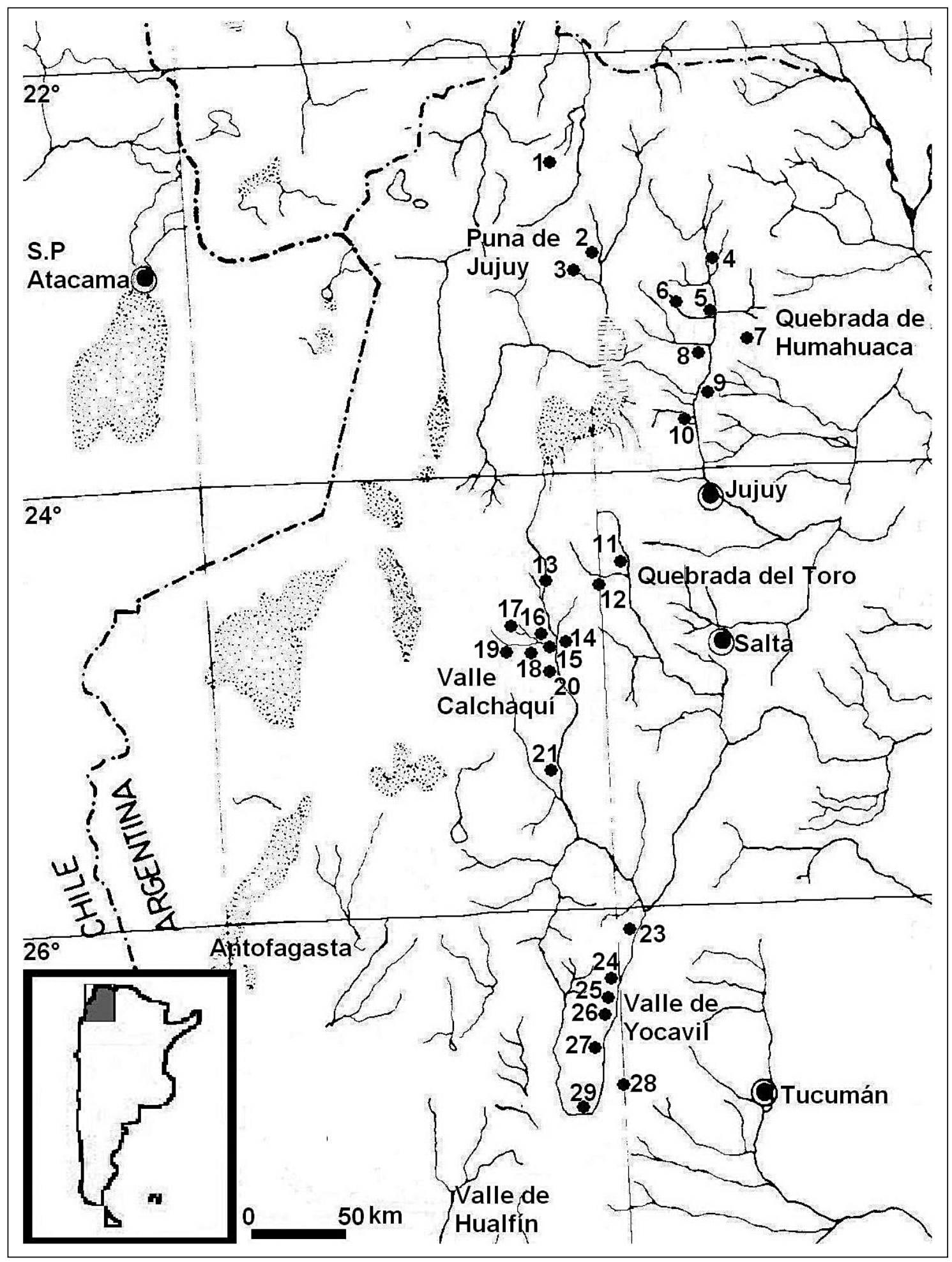

Figura 1. Principales sitios tardíos del Noroeste Argentino: 1) Pucara de Rinconada; 2) Doncellas; 3) Pueblo Viejo de Tucute; 4) Coctaca; 5) Yacoraite; 6) Los Amarillos; 7) La Huerta; 8) Juella; 9) Pucara de Tilcara; 10) Volcán; 11) Morohuasi; 12) Tastil; 13) Esquina Azul; 14) Valdéz; 15) Mariscal, Tero y Fuerte Alto; 16) Borgatta; 17) Las Pailas; 18) Loma del Oratorio; 19) Corral del Algarrobal; 20) La Paya; 21) El Churcal; 22) Molinos I; 23) Tolombón; 24) El Pichao; 25) Quilmes; 26) Fuerte Quemado; 27) Rincón Chico; 28) Loma Rica de Shiquimil; 29) Cerro Mendocino. 
y distribución de bienes, tipos de edificios y tumbas, clases de bienes de consumo y desarrollo tecnológico, entre los más importantes.

Varias han sido las revisiones y críticas que han recibido estos modelos, tales como su incapacidad para explicar el cambio entre estadios y su tendencia a homogeneizar casos distintos ocultando la variabilidad y a crear tipos muy amplios que incluyeron sociedades muy diferentes (ver Shanks y Tilley 1987). No intentaré expandir estas críticas, sino detenerme en dos de ellas:

1) Los tipos de sociedad definidos por los modelos evolucionistas son frecuentemente esencializados. Son caracterizados por una serie de indicadores arqueológicos presentados como "receta de cocina" y asumidos como "paquetes", donde la presencia de ciertos "ingredientes" indicaría la existencia de un determinado tipo de sociedad. Aunque es raro que todos los indicadores se detecten, la presencia de sólo algunos de ellos, generalmente considerados claves, es suficiente para presumir la existencia del resto y asumir la totalidad del "paquete". Más que pensar explicaciones alternativas y reflexionar sobre si la ausencia de estos indicadores es producto de diferencias históricas y culturales, los arqueólogos han argumentado que la falta de ciertos aspectos que caracterizan al tipo definido se debe a problemas de muestreo o de visibilidad arqueológica. Además, raramente se explicita cuáles son los indicadores más importantes o cuántos de ellos son necesarios para confirmar la presencia de un determinado tipo.

2) Estos modelos evolutivos, por enfocarse en los aspectos estructurales, institucionales y funcionales del proceso social, y por no interesarse en las prácticas que los sujetos desarrollan y las relaciones sociales que entablan, no consideran la interrelación subjetiva (social, simbólica, cognitiva y corporal) que las personas establecen entre sí, con los objetos y con las formas espaciales (paisajes, lugares y arquitectura). Tampoco reconocen la influencia que la materialidad y la espacialidad (o espacio social) tienen sobre el proceso social, especialmente sobre las experiencias, prácticas y relaciones sociales, así como el rol que juegan en la conformación de identidades, formas de categorizar al mundo, e ideologías. Estos modelos consideran a la cultura material y a las formas espaciales en términos funcionales y como subproductos y reflejos pasivos de la organización social y del grado de complejidad política y económica. A partir de estas ideas teóricas, los sitios arqueológicos son frecuentemente representados desde perspectivas "a vuelo de pájaro", como planos bidimensionales y puntos en un mapa que superan ampliamente la escala humana. No son vistos como lugares significativos en donde se constituía la experiencia social y se producía y reproducía la sociedad, así como también los sujetos y la subjetividad.

En los últimos 20 años, parte de la arqueología, en sintonía con los avances en la teoría social, ha comenzado a abordar el estudio de las sociedades pasadas desde el punto de vista de las personas, sus prácticas, relaciones sociales y experiencias intersubjetivas, considerando su desarrollo histórico (Pauketat 2001). De esta manera, se han abandonado las perspectivas y análisis objetivistas y sincrónicos de la sociedad, que sólo se interesan por lo estructural y/o sistémico (típicos del funcionalismo, el estructuralismo, las teorías de sistemas y las perspectivas ecológico-evolutivas), para poner el acento en la acción social y en la relación dialéctica que se establece entre estructura y agente, la cual está mediada por la práctica y es producto de la historia (Bourdieu 1977, 1999; Sahlins 1981; Giddens 1995).

Estos nuevos enfoques sobre las prácticas, la interacción y las experiencias de la gente en el pasado han comenzado a reconsiderar también la incidencia que la materialidad y la espacialidad tienen sobre la vida social y la constitución de los sujetos. Sin lugar a dudas, las prácticas, relaciones y acciones sociales se desarrollan en entornos materialmente constituidos, en relación con objetos (y a través de ellos) y dentro de espacios significativos. Desde fines de la década de 1980, y especialmente en la década de 1990, un número variado de disciplinas (entre ellas la arqueología, la antropología, la geografía, los estudios culturales y más tardíamente la sociología) han comenzado a repensar el rol que los objetos y la dimensión espacial tienen en la constitución del objeto y del sujeto social. Estos nuevos enfoques consideran que:

1) La cultura material y las formas espaciales juegan un papel activo en la conformación de la vida social. Los objetos, los paisajes y lugares no son los contenedores o elementos inertes en la dinámica social, o simples accesorios funcionales y utilitarios de las relaciones y prácticas sociales, sino que activamente producen, reproducen y transforman a las mismas (Miller 1987; Soja 1989; Lefebvre 1991; Bender 1993; Acuto 1999).

2) Existe una relación dialéctica entre las prácticas y relaciones sociales que los sujetos desarrollan, 
y los objetos y las formas espaciales que emplean para llevarlas a cabo. Mientras que las acciones y relaciones sociales producen y dan forma a la materialidad y espacialidad de manera contingente, al mismo tiempo estas últimas producen y reproducen relaciones sociales, prácticas e identidades. Además, y como parte de una relación dialéctica, el escenario en donde se realiza una práctica social y donde se entablan relaciones sociales, así como los objetos que intervienen en el desarrollo de dichas prácticas y relaciones, no son simplemente un complemento, un producto o algo añadido a éstas, sino que son una parte constitutiva de tales prácticas y relaciones sociales. La modificación o ausencia de uno de los componentes de la relación dialéctica transformaría la misma relación (McGuire 1992). Por lo tanto, si el escenario o los objetos empleados para llevar adelante una práctica variasen, dicha práctica también lo haría.

3) Tanto los objetos como las formas espaciales están significativamente constituidos; es decir, tienen significados y narrativas inscritos en ellos (Hodder 1994; Potteiger y Purinton 1998). Así, cualquier localidad adquiere su carácter de lugar no sólo por las transformaciones materiales que puedan ocurrir en la misma, sino también por los significados, emociones e historias que las personas le atribuyen y cargan; es decir, por su "sentido de lugar" (Rose 1995; Hayden 1997).

4) La interacción y aprehensión de la materialidad y espacialidad no es simplemente un proceso intelectual, sino que se da a partir de la experiencia corporal. Las personas no son espectadores externos y objetivos del mundo, sino que se constituyen como sujetos completos a partir de su inmersión mental y corporal en el mundo (Thomas 1996; Ingold 2000; Warnier 2001). La materialidad y la espacialidad dan forma de manera contingente (histórica y culturalmente) a la subjetividad y corporeidad de las personas.

Considerando todo lo anterior, el objetivo central de este artículo es repensar el Período Tardío del N.O.A. desde el punto de vista de las experiencias, prácticas y relaciones sociales que desarrollaban cotidianamente los habitantes de los grandes asentamientos conglomerados de esta época. Mi intención no es analizar los sitios desde una visión externa y cartesiana, a "vuelo de pájaro", bidimensional y mayor a la de la escala humana. Por el contrario, sostengo la necesidad de generar interpretaciones arqueológicas que incluyan a las personas actuando, moviéndose en el paisaje, interactuando con otras personas y empleando todos sus sentidos. Espero acercarme a las experiencias subjetivas e intersubjetivas que se generaban al residir en estos lugares, circular a través de ellos y percibir lo que allí pasaba. Intento así repoblar el pasado, examinando los sitios como espacios tridimensionales y significativos en donde tenían lugar la acción, las experiencias y la interacción (Thomas 1996, 2001; Bender et al. 1997; Johnston 1998; Acuto 2004, entre otros). Considerando que la cultura material y la espacialidad son aspectos activos, constituidos y constituyentes de la vida social, examino el diseño espacial y la materialidad de estos grandes poblados con el objeto de determinar qué prácticas, relaciones, experiencias y significados estos lugares habilitaban y promovían, y cuáles otros inhibían o clausuraban.

Creo que a partir de este cambio de óptica teóricometodológica podemos alcanzar interpretaciones muy distintas sobre el Período Tardío, opuestas a las que generalmente se han elaborado, para dar cuenta de esta particular época del N.O.A. Considero que en gran parte de este territorio, el Período Tardío no se caracterizó por la centralización política, la desigualdad social y la estratificación política y económica institucionalizadas, o por la presencia de jefes con poder y marcados privilegios por sobre el resto de su comunidad, aspecto que se ha exagerado y pocas veces demostrado. Incluso las investigaciones etnohistóricas contradicen esta visión de las jefaturas del N.O.A., ya que indican que durante la conquista española los jefes indígenas adquirían su posición sobre la base de sus destrezas en batalla y su habilidad política para organizar la resistencia contra los hispanos, negociar con éstos, o hacer alianzas con otros grupos indígenas (Lorandi y Boixadós 1987-1988; Raffino 1988; Sánchez y Sica 1991). Sin embargo, el cargo de jefe fue temporal, inestable y aún no consolidado, reforzándose en épocas de guerra o conflicto, para luego disolverse una vez que la situación política se modificaba. Además, el poder de acción de los jefes estaba limitado por otras instituciones, tales como consejos de ancianos (Schaposchnik 1996). De acuerdo a estos estudios, cuando las fuentes hablan de "jefes principales" se refieren a líderes nativos con habilidad para atraer seguidores y competentes para la negociación, y no a individuos con poder real y capacidad para controlar los medios de producción y extraer trabajo y el excedente de producción de su gente (Lorandi 1988). El manejo del conflicto fue la manera en que los jefes adquirían prestigio y algo de poder temporal, sin ser capaces, sin embargo, de 
mantener este poder y emplearlo para reproducir o institucionalizar su posición. Si bien esta situación ocurrió durante los primeros momentos del Período Colonial, pudo haber tenido sus raíces en el Período Tardío. Como sostiene Lorandi (2003), a pesar de que los arqueólogos suelen hablar de "señoríos" para este período, esta es una categoría social que implica una estructura mucho más compleja que la que se puede identificar a través de las fuentes históricas.

En este artículo afirmo que la integración comunal y la homogeneidad simbólica y material, así como el control y vigilancia comunal sobre el desarrollo de desigualdades, producto de una forma particular de habitar, fue un rasgo articulador de la vida social de este período. ${ }^{3}$ Sin embargo, este sentido de integración comunal y de no segregación y fragmentación social que se experimentaba en los asentamientos del Tardío pudo haber estado en tensión con luchas por obtener poder y jerarquía. Así, este parece haber sido un período de competencias por liderazgo (Palma 1998) que intentaban superar la homogeneidad estructural, más que una época de centralización y complejidad sociopolítica completamente establecida.

En esta dirección, en primer lugar, evalúo críticamente los indicadores que se han utilizado para definir a las sociedades del Período Tardío como sistemas políticos centralizados y de rangos caracterizados por la desigualdad y la estratificación política y económica institucionalizada. Luego, discuto los indicadores claves aún no detectados o que directamente no concuerdan con las expectativas arqueológicas planteadas para los modelos evolutivos. Al analizar la aplicación de dichos modelos, sigo su propia lógica de "lista de compra". Mi intención es demostrar que las evidencias empleadas para sustentar las interpretaciones sobre el Tardío son problemáticas, y varios aspectos claves que caracterizarían a una situación de desigualdad y estratificación sociopolítica y económica institucionalizada, están ausentes del registro arqueológico de este período. Por último, y a partir del análisis del habitar en los asentamientos conglomerados tardíos y de las relaciones, prácticas, experiencias y sentidos que estos lugares generaban y restringían, desarrollo una interpretación alternativa sobre la vida social en esta época.

3 Recientemente Nielsen (2006) ofrece un argumento que presenta algunos puntos en común sobre el Período Tardío con los desarrollados aquí (ver también Acuto 2004).

\section{¿Desigualdad social y estratificación económica y política institucionalizadas?}

\author{
Indicadores arqueológicos usualmente \\ considerados
}

Existen cuatro indicadores arqueológicos que han servido para interpretar al Período Tardío del N.O.A. como una época caracterizada por la complejidad y desigualdad social, y la estratificación política y económica: 1) sistemas de asentamientos compuestos por sitios de diferente jerarquía; 2) evidencias de conflictos y guerras; 3) presencia de objetos que indican especialización artesanal, y relacionado con esto, aparición de una cultura material de élite; y 4) diferencias entre las tumbas con respecto a las ofrendas depositadas. Sin embargo, hay varios problemas con estas interpretaciones: por una parte, no siempre estos indicadores aparecen combinados, y además hay dificultades teóricas y analíticas en la manera en que se han interpretado estos cuatro indicadores, que a continuación explicaré.

Se ha asumido frecuentemente que la presencia de sitios de diferente tamaño en una región reflejaría un sistema político jerarquizado y estratificación en la toma de decisiones (Tarragó 1995; Nielsen 1996, 2001; DeMarrais 1997, 2001; Nastri 1997-1998; Sempé 1999; Tarragó y Nastri 1999). Empleando la lógica de los modelos de lugar central o de rango-tamaño, así como algunos otros análisis provenientes de la cartesiana geografía formal, el sitio más grande de la región ha sido considerado la cabecera política, mientras que los sitios menores, de segundo y tercer orden, han sido vistos como asentamientos satélites, dependientes y proveedores del centro principal. Además de diferencia en los tamaños, se esperaría que los sitios de un sistema de asentamiento jerarquizado no sólo varíen en sus funciones, sino especialmente en su infraestructura interna. Así, las cabeceras deberían concentrar la infraestructura administrativa, política y de control de recursos, y constituir el lugar de residencia de la élite. Sin embargo, y como se discutirá mas adelante, aunque existen sitios de diferentes tamaños y funciones asignables al Período Tardío, en varias regiones no se registran claras diferencias de infraestructura entre aquellos de distintos tamaños. Por otra parte, recientes investigaciones señalan que los sitios de distintos tamaños no habrían sido contemporáneos. Rivolta (2007) sostiene que en la quebrada de Humahuaca los asentamientos medianos y pequeños habrían sido abandonados hacia el siglo 
XIII, para luego habitar casi exclusivamente en los grandes sitios conglomerados.

En el caso de la guerra y el conflicto, se ha supuesto que estas circunstancias propiciarían el surgimiento de líderes encargados de organizar a su comunidad, quienes, como consecuencia, adquirirían poder y prestigio. La tendencia a ocupar lugares altos y de difícil acceso, así como la presencia de fortalezas defensivas, ha llevado a caracterizar al Tardío como una época de conflictos entre comunidades y regiones (Tarragó 2000). No obstante, y como he argumentado, los estudios etnohistóricos señalan que en el contexto social del N.O.A. durante esta época las guerras no habrían necesariamente favorecido el surgimiento de una élite institucionalizada con control sobre la toma de decisiones y acceso preferencial a recursos.

La especialización artesanal ha sido considerada indicadora de complejidad, desigualdad y estratificación por dos razones: 1) señalaría que al menos algunas personas no necesitaban trabajar en otras actividades (p.e., en la producción de bienes primarios) y que su trabajo estaba auspiciado por otros sujetos con recursos suficientes como para mantenerlas; 2) los productores especialistas habrían estado asociados con una economía de bienes de prestigio en la cual los objetos especiales que manufacturaban, que implicaban un conocimiento particular y mayor inversión de trabajo en comparación con otros artefactos, servían a quienes auspiciaban a estos productores para distinguirse del resto, establecer su estatus superior y constituirse como una élite (Brumfiel y Earle 1987). De acuerdo con los modelos evolutivos citados, en las jefaturas y los Estados, estos especialistas estaban asociados y dependían de las élites, produciendo bienes de prestigio para éstas. Creo que es aún problemático asumir que la especialización artesanal de tiempo completo estuvo ampliamente desarrollada en el N.O.A. durante el Tardío. Esto no significa que haya estado ausente, pero sí que fue más restringida de lo que se ha supuesto.

Uno de los problemas referidos al tema de la especialización es de tipo teórico. Se suele creer que la mera presencia de un objeto que muestra signos de producción especializada implica la existencia de una élite que se apropió de estos bienes (ver Raffino 1988; González 1997; Tarragó 2000; DeMarrais 2001; Nielsen 2001). Sin embargo, esta apropiación debe ser demostrada, al igual que debe explicarse cómo, para cada caso, un grupo se apropia de la producción de otro. Además, demostrar que ciertos bienes fueron empleados para crear distinción y reafirmar el estatus de un grupo, no implica que su sola existencia legitimaba la posición de las élites, tal como se ha asumido (Nielsen 1996; Tarragó y González 1996; González y Peláez 1999). Esta idea implica una fetichización de la cultura material y un uso funcionalista y superficial del concepto de ideología.

Hay también algunos problemas analíticos en la interpretación de las evidencias de especialización. En primer lugar, la mayor parte de la cultura material del Tardío no fue fruto de producción especializada. Muchos de los artefactos más significativos elaborados en esta época (algunos de los cuales, por su ubicuidad, pueden ser considerados emblemáticos de las culturas del período) no fueron hechos por especialistas. La evidencia arqueológica indica que las vasijas cerámicas se manufacturaron a nivel doméstico. Asimismo, y a diferencia de los períodos Temprano y Medio cuando la cerámica decorada fue de excelente calidad y mostraba una importante inversión de trabajo en su elaboración, la gran mayoría de la alfarería tardía no requirió una gran inversión de energía, y su manufactura no involucró muchas etapas en su cadena productiva. La producción textil también se desarrolló dentro de la esfera doméstica y no en talleres especializados. Por otra parte, hay un número importante de objetos de madera, algunos de los cuales son tallas de buena manufactura, tales como tabletas y tubos para aspirar alucinógenos, sin embargo, no hay evidencia que avale que fueron producto de actividades especializadas. En segundo lugar, si bien la metalurgia es generalmente considerada una actividad especializada que demandaba un particular tipo de conocimiento y una inversión importante de tiempo, también se ha señalado que en varias regiones la producción de artefactos de metal involucró una tecnología simple que no requería de técnicas o instrumental complejos, sino que era llevada a cabo con crisoles pequeños y fácilmente manejables por unidades domésticas (Baldini 1992; Tarragó 1992; D’Altroy et al. 2000; Angiorama 2001, 2005; Nielsen et al. 2004). ${ }^{4}$ Aunque el uso de crisoles no necesariamente implica bajos niveles de producción (Tarragó y

\footnotetext{
4 Angiorama (2001: 39) señala que la mayoría de los minerales utilizados en la quebrada de Humahuaca podían fundirse con métodos relativamente sencillos.
} 
Nastri 1999), sí demuestra que no se necesitó de una infraestructura y un conocimiento sofisticado. Sumado a esto, se comprobó en varios casos que las actividades metalúrgicas fueron efectivamente realizadas a nivel doméstico y desarrolladas directamente en los complejos residenciales (D’Altroy et al. 2000; Nielsen 2001; Angiorama 2005). ${ }^{5} \mathrm{En}$ tercer lugar, hay pocas evidencias sólidas de producción metalúrgica a gran escala como para sostener que su especialización fue un rasgo ampliamente difundido durante el Período Tardío. El caso más notable es, sin duda, el de Rincón Chico (valle de Yocavil), donde se detectó un taller metalúrgico con indicadores de equipamiento para producción intensiva y a gran escala, no orientada al consumo doméstico (Tarragó y González 1996; González 1997). De todos modos, por ahora Rincón Chico es un caso atípico. En cuarto lugar, en muchas regiones del N.O.A. la mayor parte de los objetos de metal no muestran signos de especialización, sino que son pequeños artefactos utilitarios. ${ }^{6}$ Los objetos de metal más complejos son los discos y campanas decoradas, cuya producción involucró una importante inversión de trabajo y un tipo especial de conocimiento. Tarragó y González (1996) han sostenido que estos artefactos estuvieron relacionados con la guerra, pero, si fuera así, los artefactos de metal de mayor elaboración e inversión de trabajo habrían estado relacionados con una actividad que creaba distinción, pero que no necesariamente generaba desigualdades y estratificación institucionalizadas.

5 Angiorama (2005) cuestiona la idea de que la producción de bienes de metal estuvo apropiada y controlada por una élite. A través de excavaciones de contextos domésticos en Los Amarillos (uno de los poblados principales y de mayor tamaño de la quebrada de Humahuaca) y de un minucioso análisis de la evidencia recuperada con anterioridad en la región, el autor demuestra que: a) las unidades domésticas contaban con tecnología, herramientas, acceso a las fuentes y recursos suficientes para producir objetos de metal; y b) no hubo restricción aparente en el acceso a objetos metálicos, tanto utilitarios como ornamentales, cuya amplia distribución y presencia en una variedad de contextos indicaría que el acceso a ellos no fue exclusivo de una minoría privilegiada $\mathrm{y}$ con poder.

6 Contrariamente a esto, González y Peláez (1999) han demostrado que la mayor proporción de metal era empleada para confeccionar bienes ornamentales, especialmente discos. Sin embargo, su análisis se basa en objetos provenientes de las tumbas (no fechadas) de La Paya y Pucara de Tilcara, dos sitios con fuerte influencia incaica. Por lo tanto, resta aún determinar si la manufactura de objetos ornamentales fue una práctica del Tardío o causa de la intervención incaica.
Relacionado con la especialización artesanal, algunos autores sostienen que durante el Período Tardío la aparición de una cultura material de élite de carácter interregional, probaría la existencia de desigualdad estructural y estratificación. Nielsen (1996) afirma que es en este período cuando comienzan a aparecer objetos especiales manufacturados con materiales escasos o alóctonos en la quebrada de Humahuaca (p.e., equipos de inhalar alucinógenos, adornos de metales preciosos y piedras semipreciosas e instrumentos de cobre o bronce); bienes que, por otra parte, fueron encontrados en las tumbas de pocos individuos. Argumenta además que artefactos similares fueron usados por las élites de otras regiones para marcar distinción, e incluso sugiere que el auge del tráfico a larga distancia estuvo más relacionado con la necesidad de las élites por conseguir estos ítems que con requerimientos económicos.

Hay varios aspectos que demandan una revisión de esta interpretación. Muchos de estos objetos no son nuevos, sino que están circulando previamente $\mathrm{y}$ aparecen en tumbas de sociedades que han sido caracterizadas como menos complejas y estratificadas. Asimismo, el consumo de alucinógenos es una práctica anterior al Período Tardío. Debería explicarse entonces por qué se considera que estos objetos ahora, y no antes, constituyen parte de las estrategias de ciertas personas para distinguirse de las demás y construir su poder. Por otra parte, interpretar de esta manera al tráfico a larga distancia es demasiado simple. El intercambio es una práctica compleja que no está solamente ligada con estrategias políticas. Como lo ha demostrado la etnografía, el intercambio implica un entrelazamiento de distintas esferas de producción y reproducción de la vida social, en donde se involucran necesidades económicas (p.e., obtención de obsidiana), religiosas (trayectorias a través del paisaje), ideológicas (tejer redes entre comunidades por diferentes motivos), políticas y de reproducción social (Lazzari 1999). Además, se ha probado que productos foráneos como la obsidiana y el estaño (empleado para producir bienes de bronce, considerados de prestigio) estuvieron ampliamente distribuidos en algunas regiones (Acuto 2004; Angiorama 2005). Además, falta explicar por qué y cómo estos objetos legitimarían la posición privilegiada de la élite, ya que crear distinción es una cosa y legitimarla, como sostiene Nielsen (1996), es otra. Por último, incluir a las tumbas en estos análisis es problemático tanto por razones teóricas como por la forma en que se ha analizado la evidencia. 
En efecto, se ha asumido, siguiendo los modelos funcionalistas de la arqueología procesual, una relación directa entre la inversión en el ritual fúnebre y el estatus social, suponiendo que las tumbas constituyen un reflejo directo del estatus de la persona enterrada y, por lo tanto, de la organización social y nivel evolutivo alcanzado por la sociedad. De esta manera, aunque prácticamente no se detectaron diferencias constructivas entre las tumbas tardías (ver Ambrosetti 1907-1908; Cigliano 1973; Palma 1998, 2003), la distribución diferencial de las ofrendas fue interpretada como indicador irrefutable de desigualdad social y de una sociedad de rangos.

En cuanto a los aspectos teóricos, el análisis mortuorio procesual ha sido criticado por su visión instrumental de la ideología, su concepción pasiva de la cultura material y por otorgarle agencia sólo a las élites. Si bien las prácticas funerarias ponen en juego estrategias de los vivos, no involucran una única estrategia (representar el estatus social), ni la estrategia de un solo grupo (la élite). Se ha demostrado ampliamente a través de casos arqueológicos, etnográficos e históricos que las prácticas funerarias no siempre buscaron afirmar, y la tumba reflejar, el estatus del muerto y, por lo tanto, esta idea no puede ser generalizada transhistórica y transculturalmente. Aunque hay casos en que las élites invirtieron en el ritual mortuorio para marcar su jerarquía, representando las tumbas el estatus del occiso, en muchas otras circunstancias esto no ocurrió. El ritual funerario puede estar conectado con diversos campos de la vida social, y así la tumba representar otros aspectos de la organización social, tal como negociaciones entre géneros, ciclos de vida, aspectos de la biografía del muerto, creencias religiosas, cosmovisiones particulares sobre la muerte, relación entre persona y comunidad, mistificación, reificación, negación o inversión de la organización social (ver Parker Pearson 2000). Además, todos los agentes sociales y no sólo las élites pueden desarrollar estrategias durante los rituales funerarios orientadas a enmascarar, naturalizar, criticar, negar o resistir la organización social de los vivos.

Respecto a los problemas analíticos, los modelos procesuales son relevantes para tumbas individuales donde se invertía en definir y destacar el estatus de personas particulares, y no para tumbas colectivas (como lo son la mayoría de las tumbas del Período Tardío), las cuales pueden estar involucradas en procesos ideológicos diferentes (ver Shanks y Tilley 1982). Por otra parte, no hay en el registro arqueológico del período monumentos mortuorios que hayan servido para inmortalizar a un individuo separándolo del resto de la comunidad, creando una memoria hegemónica de su persona y sus logros. No hay enterratorios que por su localización y arquitectura se separen y diferencien de los demás. No se han encontrado tumbas que hayan involucrado una amplia movilización de mano de obra y que por su monumentalidad y solidez (que implica perduración en el tiempo) legitimen el rango de los descendientes. ${ }^{7}$ Tampoco, en la mayoría de los casos, las prácticas funerarias parecen haber sido rituales comunales asociados con actos políticos orientados a justificar o naturalizar rangos. No fueron actividades desarrolladas en espacios públicos (salvo pocas excepciones) y que hayan involucrado acciones de consumo conspicuo o tácticas para agrandar la figura del muerto (como la monumentalización). Por el contrario, estas prácticas estuvieron estrechamente relacionadas con la esfera doméstica y, por lo tanto, con la reproducción social y simbólica de las unidades domésticas y los linajes más que con procesos políticos. Aunque hay algunos casos que presentan sectores de cementerios, la mayoría de los enterratorios se asocian a los complejos residenciales. Además, los cementerios se encuentran a corta distancia de los sitios y, por lo tanto, asociados con los poblados. ${ }^{8}$ Sumado a lo anterior, la mayor proporción de los objetos ofrendados fueron de uso doméstico y cotidiano. Finalmente, las evidencias indican una gran variabilidad de tipos de enterratorios ${ }^{9}$ y no un patrón orientado a reflejar

$7 \quad$ Si bien hay tumbas en montículos (DeMarrais 1997; Tartusi y Núñez Regueiro 2001), éstos eran estructuras de poca complejidad constructiva y tamaño reducido.

8 Por ejemplo en La Huerta, el 80\% de las tumbas está en los patios de los complejos residenciales (Raffino y Alvis 1993: 46). En el Pucara de Tilcara hay una necrópolis que parece haber sido contemporánea a algunos entierros en sectores domésticos, pero éstos fueron los más frecuentes y se prolongaron durante toda la ocupación del sitio (Rivolta com. pers. 2007). En Volcán, el cementerio se encuentra a corta distancia de los recintos. En Tastil, la mayoría de las tumbas está relacionada con las casas (Cigliano 1973: 95). En muchos sitios del valle Calchaquí Norte, las tumbas se asocian con la esfera doméstica (Tarragó 1977; Díaz 1978-1980 Ms). En La Paya, casi la mitad de las tumbas excavadas están en los complejos residenciales, y el resto, en un cementerio adyacente al sitio (Ambrosetti 1907-1908). Esto no se da en Molinos I, al sur del valle Calchaquí (Baldini 1992).

9 En cistas en cementerios, en cistas dentro de los complejos residenciales, en cistas circulares o cuadrangulares, en urnas, directos en fosas, en grutas o cavidades rocosas, primarios, secundarios, simples, múltiples, de adultos solos, de adultos con niños en urnas, con ajuar, sin ajuar, con gran cantidad de objetos, con pocos objetos, con objetos variados, con ob- 
y reificar en la muerte el estatus de los vivos. Todo esto indica que el ritual funerario durante el Tardío fue una práctica compleja que no puede reducirse a una sola estrategia relacionada con representar los distintos estratos sociales y marcar distinción de rangos. Esta variabilidad sugiere que estrategias disímiles fueron puestas en juego por los vivos, y que las tumbas estuvieron entrelazadas con otras esferas sociales, más que con la política.

\section{Indicadores arqueológicos ausentes}

A pesar de que varias investigaciones han intentado detectar otros marcadores para sostener la idea de la existencia de rango, estratificación y desigualdad institucionalizada durante el Tardío, varios indicadores claves parecen estar ausentes del registro arqueológico del período.

En primer lugar, no hay evidencias de movilización, control y administración de la producción de bienes primarios o de la apropiación de la producción excedentaria que podrían haber servido para financiar y asegurar la posición de las élites y sus instituciones. No se han encontrado rastros de almacenaje centralizado, siendo esta actividad desarrollada a nivel doméstico, en pequeñas estructuras de piedra, en pozos o en ollas (Raffino 1988). En mis propias investigaciones en el valle Calchaquí Norte (ver Figura 1), los relevamientos sistemáticos en los asentamientos Mariscal y Las Pailas no detectaron complejos de almacenes, como sí sucede en sitios incaicos. Tampoco los han detectado otras investigaciones en otros sitios tardíos de la misma región, tales como La Paya (González y Díaz 1992), Tero (Díaz 1978-1980 Ms), Corral el Algarrobal, Ruiz de los Llanos, Buena Vista y Borgatta (DeMarrais 1997), Valdez (D’Altroy et al. 2000) o del área de La Poma (Gifford 2003). Sumado a esto, excavaciones en un complejo residencial de Las Pailas señalaron que el almacenaje se realizaba al interior del patio (Tarragó 1977: 506).

En varios sitios de la Puna de Jujuy se ha comprobado que las actividades de almacenaje tenían lugar en los complejos residenciales. ${ }^{10}$ Este almacenaje

jetos similares, etc. (Ambrosetti 1907-1908; Cigliano 1973; Díaz 1978-1980 Ms; Alfaro 1983; Garay 1998; Palma 1998; Johansson 2001; Cornell y Fahlander 2002).

10 Por ejemplo, en Pueblo Viejo de Potrero (Albeck et al. 1999, 2001), Pueblo Viejo de Tucute (Albeck 1997) y Doncellas (Ottonello 1973). doméstico se realizaba en estructuras circulares pequeñas o en ollas. Más de 100 años de trabajo arqueológico en la quebrada de Humahuaca no han detectado complejos de almacenes, y en varios casos se comprobó que esta actividad se llevada a cabo en el ámbito doméstico. En La Huerta (Figura 2), uno de los sitios más importantes de esta región, no hay evidencias de almacenaje centralizado (Palma 1998); tampoco en Juella (Nielsen et al. 2004) y Volcán, en donde, además, se comprobó que era a nivel doméstico (Garay 1998). En un complejo residencial excavado casi en su totalidad en el Pucara de Tilcara, se encontraron también evidencias de almacenaje (Tarragó 1992).

Tastil fue el poblado principal de la quebrada del Toro. Se ha propuesto que varios sitios cercanos orientados a la producción agrícola lo proveyeron de recursos (Cigliano y Raffino 1973). Sin embargo, no hay en Tastil concentraciones de depósitos, sino que cada unidad doméstica almacenaba sus propios bienes (Cigliano 1973). Tampoco hay en los sitios agrícolas evidencias de depósitos que pudieron haber sido objeto de control. Por ello se ha sostenido que lo cosechado era llevado directamente a Tastil y distribuido entre sus habitantes (Raffino 1972: 204). En el sector medio del valle Calchaquí, el sitio de Molinos I, uno de los asentamientos más investigados de esta área, tampoco presenta almacenaje centralizado (Baldini 1992), al igual que otros sitios del valle Calchaquí Sur, tales como Tolombón (Williams 2003), y del valle de Yocavil como El Pichao, Quilmes y Rincón Chico (Tarragó 1995; Bengtsson 2001a).

En segundo lugar, no se han encontrado en los principales asentamientos del período sectores político/ administrativos demarcados y segregados de los complejos residenciales, ni edificios o estructuras cuyas dimensiones, diseño y calidad constructiva indiquen la presencia de instituciones políticas centralizadas, o demuestren la existencia de un nivel de toma de decisiones por encima de la comunidad o de las unidades domésticas. En este sentido, no podemos afirmar que un grupo administrador tiempo completo y liberado de las actividades primarias haya estado presente en los asentamientos de esta época. Tampoco hay evidencias de estructuras monumentales que representen trabajo controlado, movilizado y orientado hacia la esfera política, es decir, trabajo coactado y apropiado por un individuo y su unidad doméstica con el propósito de agrandar su figura y aumentar su poder. Contrariamente a 


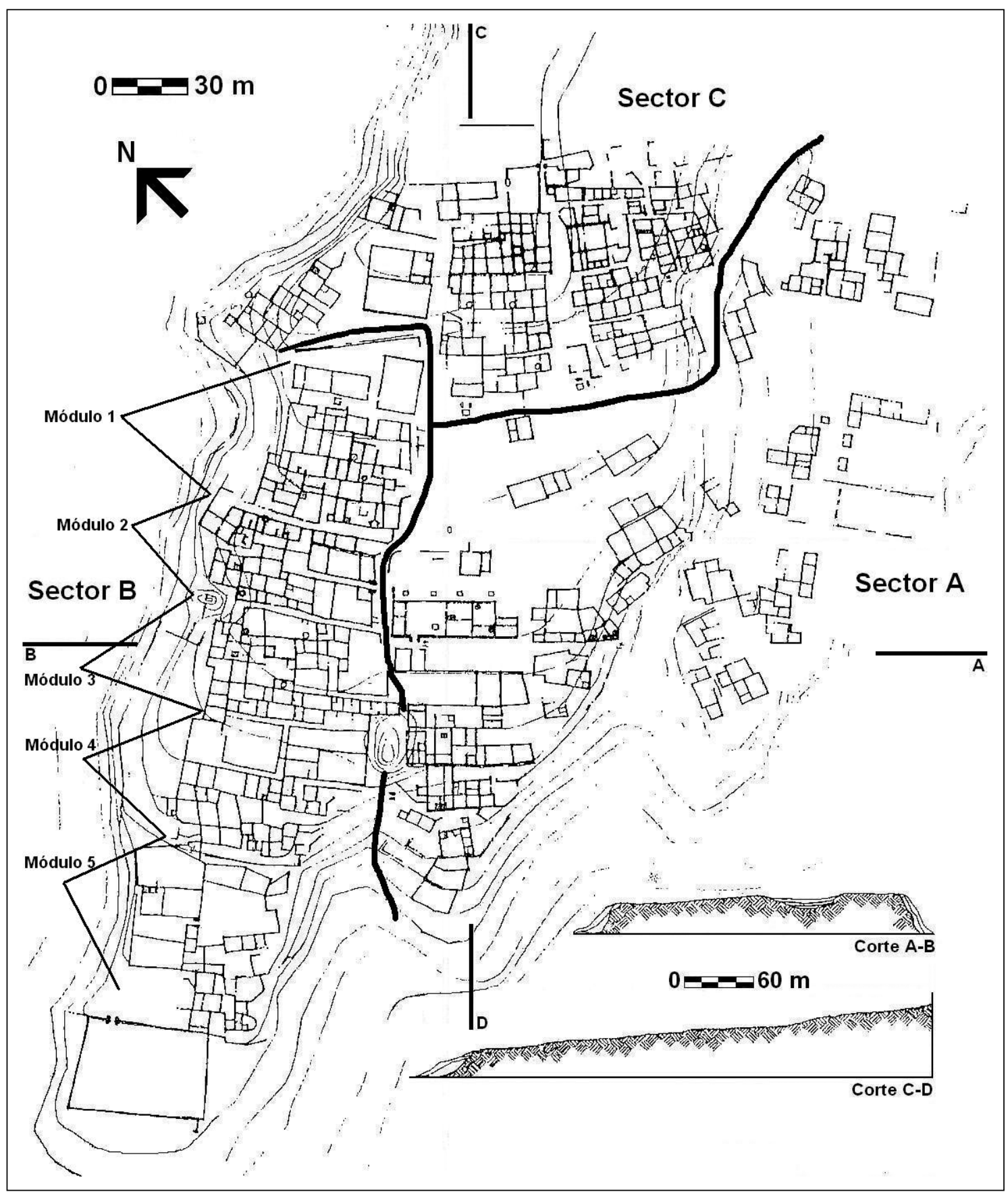

Figura 2. Plano de La Huerta, quebrada de Humahuaca. Cortesía de Jorge Palma.

lo que sucede en los Andes Centrales, aquí no hay construcciones como pirámides, plataformas o tumbas reales, que hayan servido para representar e intentar legitimar el poder de la élite gobernante. No se ha encontrado este tipo de estructuras en ninguno de los sitios tardíos estudiados en el valle Calchaquí Norte; tampoco en muchos de los principales centros poblados de la Puna de Jujuy, la quebrada de Humahuaca, o el valle Calchaquí Medio. Incluso investigadores del Período Tardío en la parte sur de los valles calchaquíes, han destacado la ausencia de sectores político/administrativos o construcciones monumentales en sitios como Tolombón y el Pichao (Bengtsson 2001a). 
No obstante, y a partir de algunos pocos casos de aterrazamiento masivo para la producción agrícola (p.e., en algunos sitios de la Puna de Jujuy, en Coctaca y Alfarcito en la quebrada de Humahuaca, y en El Pichao en el valle de Yocavil), se ha señalado que la complejidad de estas obras sugeriría un nivel de organización con cierto grado de jerarquización (Albeck 2001; Stenborg 2001).

Si bien estas construcciones debieron ser producto de trabajo coordinado, esto no necesariamente implica la existencia de poder y jerarquía institucionalizada y de marcadas diferencias sociales, ya que también pueden ser producto de trabajo comunal y redes de solidaridad y cooperación (Pauketat 2000). Además, se ha sostenido que algunas de ellas pueden haber sido producto de la intervención incaica.

Existen, por supuesto, casos de estructuras "especiales" en varios sitios tardíos del N.O.A., que pudieron estar relacionadas con actividades ceremoniales y comunales, tales como grandes recintos o montículos con muros de contención, rampas o escalones para su acceso, conectados o enfrentando espacios abiertos, y en algunos casos, claramente separados de los sectores residenciales. Sin embargo, ninguna de estas construcciones es excepcional, monumental o involucró una inversión considerable de trabajo. Tal es el caso de las estructuras "especiales" encontradas en Doncellas (Alfaro 1983: 26) y Pueblo Viejo de Tucute, en la Puna de Jujuy (Albeck et al. 1999), en Volcán, en la quebrada de Humahuaca (Garay 1998), y en El Pichao, en el norte del valle de Yocavil (Tartusi y Núñez Regueiro 2001). Respecto al valle Calchaquí Norte, DeMarrais $(1997,2001)$ ha destacado la presencia de montículos de tierra con muros perimetrales en algunos sitios, sosteniendo que los mismos son prueba de "la materialización del trabajo corporativo y del poder de un jefe".

En la investigación que estoy desarrollando he puesto especial atención en estas estructuras "especiales" que, de acuerdo a DeMarrais demostrarían la existencia de desigualdad social en esta época. He observado que estas estructuras monticulares son comunes en los sitios tardíos de la región habiendo más de una por sitio. No presentan forma regular, ni ocupan lugares especiales o centrales en los asentamientos, sino que se asocian a los complejos residenciales y distan de ser obras monumentales (Figura 3). En general no son de gran tamaño, no llegando a superar los $6 \mathrm{~m}$ de alto (aunque la mayoría son menores) y su construcción no habría implicado una gran inversión de trabajo ya que la tierra movilizada es poca. Sus muros perimetrales son pequeños muretes de contención para evitar su derrumbe. Trabajadores locales actuales con conocimiento en construcción y albañilería confirmaron que la edificación de estos montículos no les habría demandado a cinco trabajadores más de dos o tres días de trabajo. Todo esto indica que dichos montículos no son representaciones materiales del poder de un jefe y de la movilización de mano de obra a gran escala. Por el contrario, nuestros estudios señalan que estos montículos se formaron por la acumulación del sedimento excavado para construir los recintos semisubterráneos y/o la acumulación de basura generada en las residencias.

El valle de Yocavil, sin embargo, parece ser una excepción. Rincón Chico, el sitio más estudiado del valle, cuenta con varios sectores separados y funcionalmente distintos, por lo que se ha argumentado que su patrón de asentamiento es jerarquizado (Tarragó 1987, 1995). Entre los diferentes sectores destaca un área ceremonial cuidadosamente planificada y segregada de las áreas residenciales, que cuenta con una plataforma ceremonial construida con hileras de rocas de tres colores distintos e infraestructura relacionada con observaciones astronómicas. Destacan las características acústicas y escenográficas del diseño del sector ceremonial del sitio (donde las vistas y los movimientos fueron orientados), así como su cuidada manufactura, la inversión de trabajo empleado en su construcción y su relación con actividades ceremoniales relacionadas con los ciclos anuales (Reynoso 2003). Además, el diseño espacial de este sector propició la división entre los conductores de los rituales y los observadores.

En tercer lugar, muchos poblados destacados del Período Tardío no cuentan con plazas o espacios públicos formalizados. Las plazas tuvieron un rol destacado en la reproducción de relaciones sociales y estructuras de poder en las sociedades estratificadas de los Andes. Los espacios públicos eran el escenario de fiestas y celebraciones en las cuales se activaban mecanismos de redistribución de bienes y servicios. En estos contextos, las élites negociaban el apoyo y favores de su comunidad o seguidores, ofreciendo comidas y regalos. Asimismo, utilizaban estos rituales para legitimar las desigualdades existentes. Estas plazas suelen tener un diseño formalizado, ocupar un lugar central del sitio y estar conectadas con arquitectura pública y de poder. Sin embargo, las aldeas y pueblos tardíos no estuvieron organizados en torno de un espacio público 


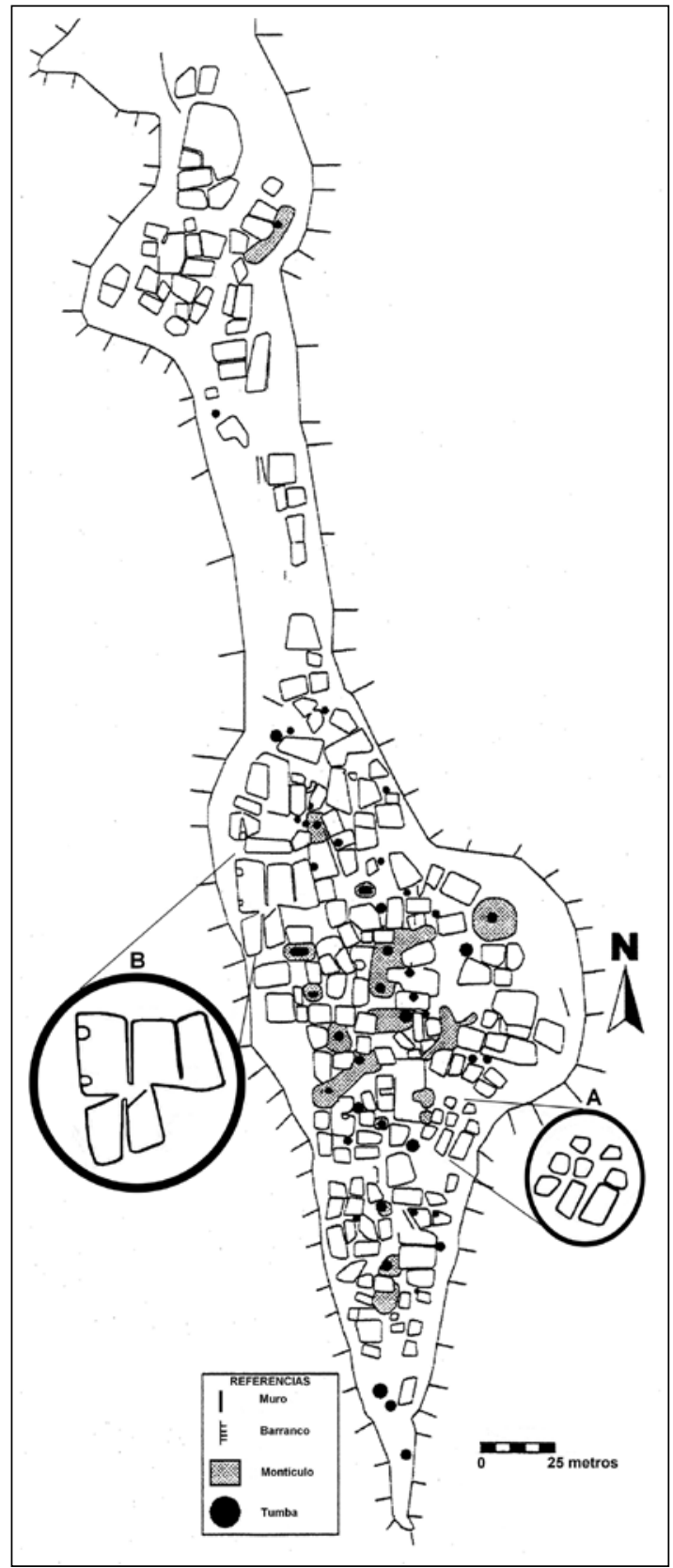

Figura 3. Plano de Mariscal, valle Calchaquí Norte.

central y formalizado o a estructuras especiales que pudieran haber actuado como axis mundi. ${ }^{11} \mathrm{Si}$ bien

11 Bengtsson (2001b) coincide con este punto, indicando que no pudo reconocer la presencia de plazas en varios sitios del valle de Yocavil, como El Mollar, Talapazo, Tolombón, Fuerte Quemado, Quilmes y El Pichao. Además argumenta que los sitios de la Cultura Santa María no tienen centros o puntos focales. hay espacios abiertos que pueden ser considerados plazas en algunos de los principales asentamientos tardíos, en la mayoría de los casos sólo se trata de espacios abiertos de forma irregular, sin un diseño formal y sin conexión con edificios administrativos (Figura 4). Resulta destacable que en muchos de los principales sitios tardíos hay más de un espacio abierto o estructuras de grandes dimensiones que pudieron haber cumplido perfectamente el rol de espacio público. En algunos casos son espacios abiertos sin diseño formal aparente, mientras que en otros son estructuras rectangulares de grandes dimensiones, asociadas a uno o varios complejos residenciales. Algunos ejemplos son Pueblo Viejo de Potrero, Ojo de Agua y Pueblo Viejo de Tucute, en la Puna de Jujuy (Albeck et al. 1999, 2001; Dip 2001); Los Amarillos (Nielsen 2001), Juella (Nielsen et al. 2004), La Huerta y Volcán (Garay 1998) en la quebrada de Humahuaca, aunque el último cuenta con un montículo particular; Tastil en la quebrada del Toro (Cigliano y Raffino 1973; Cigliano 1973); Las Pailas, La Paya, Valdez, Buena Vista, Ruiz de los Llanos y posiblemente Borgatta ${ }^{12}$ en el valle Calchaquí Norte; y El Pichao (Stenborg 2001) y Loma Rica en el valle de Yocavil (Tarragó 1995).

Si realmente estos espacios abiertos se utilizaron para realizar actividades públicas y ceremoniales es algo que aun debe demostrarse, porque si así fuera, indicaría una falta de centralización política. La presencia de más de una plaza sugeriría que en los poblados del Período Tardío existió más de un grupo, facción o familia extensa auspiciando fiestas y ceremonias, y compitiendo por poder y prestigio dentro de la misma comunidad. Por lo tanto, no estaríamos ante la presencia de sociedades de rangos marcadamente centralizadas, sino de comunidades en las cuales aún se competía por el liderazgo y donde las posiciones todavía debían ser negociadas. Un ejemplo de esto es La Huerta (ver Figura 2). La parte no incaica y tardía del sitio (sector B) presenta al menos cuatro o cinco módulos de estructuras conglomeradas divididos entre sí por senderos. ${ }^{13} \mathrm{El}$ primero desde el sur tiene más estructuras grandes, interpretadas

12 Aunque en este sitio hay un gran espacio rectangular destacado, su forma y diseño sugiere que es producto de la influencia incaica (DeMarrais 2001).

13 El sector $\mathrm{C}$ del sitio también repite este patrón, aunque en este caso los investigadores sostienen sobre la base de fechados obtenidos de un basural asociado y de recolecciones de superficie, que su ocupación, al igual que la del sector A, ocurrió en tiempos incaicos (Palma 1998). 


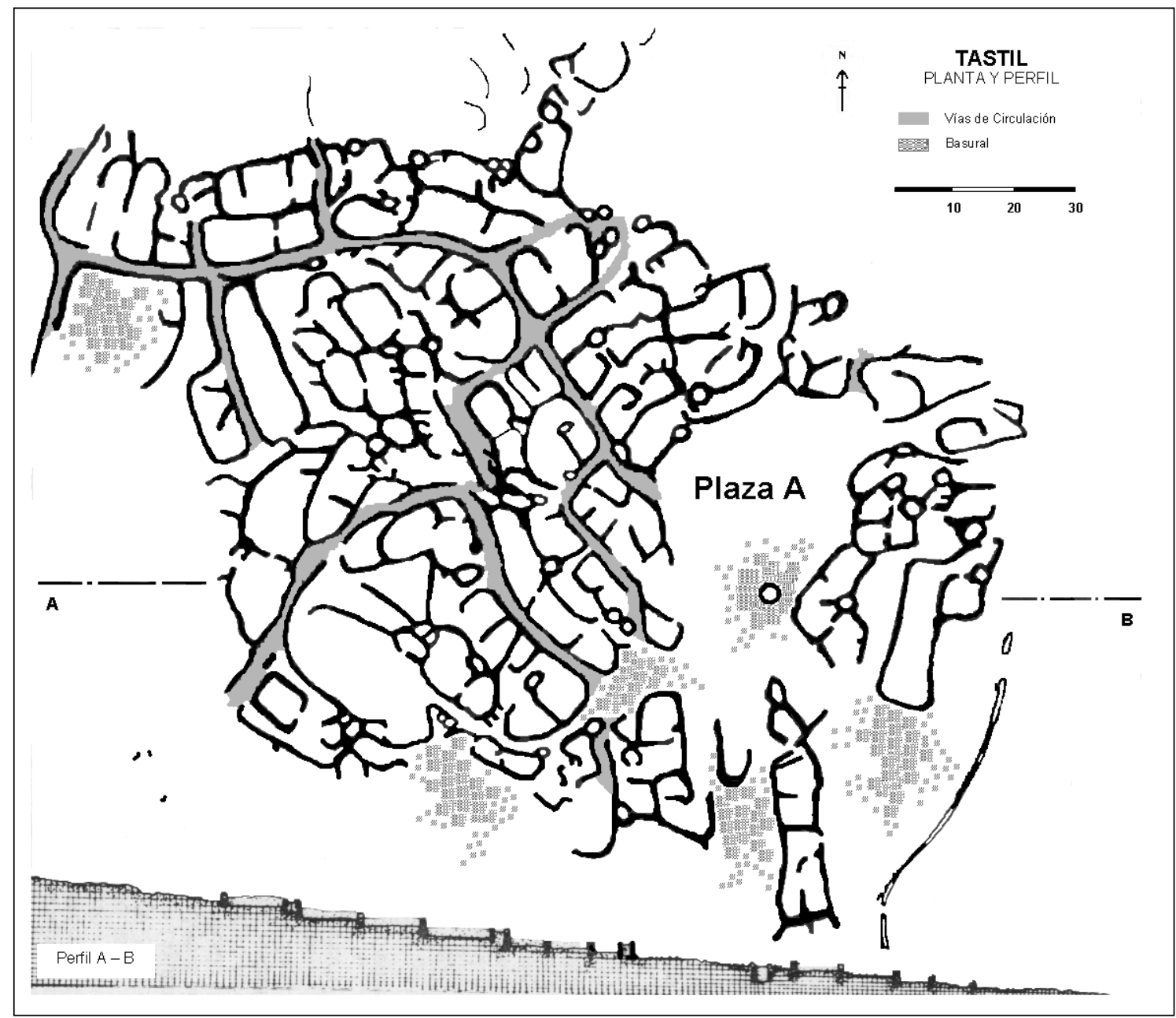

Figura 4. Plano parcial de Tastil, quebrada del Toro. Modificado de Raffino (1988: 88).

como corrales (Raffino y Alvis 1993). En cada uno de estos módulos hay más de una estructura grande que pudo perfectamente haber servido como espacio público o de reuniones. Es posible que cada uno de estos conjuntos edilicios tan definidos haya sido el espacio de vivienda y actividades de familias extensas o facciones políticas que convivían en un mismo lugar, pero que también competían, dentro de los límites de la estructura social, por obtener seguidores y acumular poder.

En cuarto lugar, en la Puna de Jujuy, la quebrada de Humahuaca, la quebrada del Toro y el valle Calchaquí Norte y Medio, los sitios tardíos no están divididos en sectores jerárquicamente distintos, sino que se presentan como grandes y uniformes conglomerados de complejos residenciales interrumpidos en algunos sectores por espacios abiertos o estructuras mayores y sin techo, que se han caracterizado como plazas o espacios de participación comunitaria. En estos poblados, el complejo residencial (en ocasiones semisubterráneo), conformado por un número variable de recintos asociados a un patio abierto, constituye la unidad edilicia básica. Los asentamientos parecen haber crecido a partir de una disposición celular de estos complejos residenciales (ver Figura 4), los cuales se acomodaron uno al lado del otro. Estos grandes asentamientos conglomerados presentan un trazado y una arquitectura llamativamente homogéneos, especialmente en cuanto a formas y técnicas constructivas. ${ }^{14} \mathrm{Al}$ parecer, esto no ocurre

\footnotetext{
14 Varios investigadores destacan esta homogeneidad, como Albeck y colaboradores (1998) para Pueblo Viejo de Tucute en la Puna de Jujuy; Nielsen (2001) para los sitios de la quebrada de Humahuaca durante el Período de Desarrollos Regionales I, y en esta misma región Garay (1998: 133) para Volcán, Leibowicz (2006) para La Huerta preincaica, Madrazo
} 
en regiones de más al sur, como el valle de Yocavil o el centro de la provincia de Catamarca, donde los sitios no son conglomerados continuos de recintos sino que se dividen en sectores distanciados entre sí, y con distintas funciones y diferentes jerarquías. Este es el caso de El Pichao (aunque no hay diferencia jerárquica entre sus sectores siendo su arquitectura homogénea), Tolombón, Quilmes y Rincón Chico, entre otros (Tarragó 1987; Nastri 1999; Sempé 1999; Bengtsson 2001a; Williams 2003).

Relacionado a lo anterior, en varios asentamientos tardíos no se han encontrado marcadas diferencias entre los complejos residenciales, no registrándose viviendas significativamente diferentes del resto en términos de su estilo arquitectónico y calidad constructiva (Raffino 1988), ni de su localización dentro del sitio (p.e., controlando espacios públicos y almacenes, o en sectores más altos), siendo la arquitectura doméstica bastante uniforme, aunque resta aún investigar diferencias en tamaño y cantidad de estructuras. En Las Pailas y Mariscal en el valle Calchaquí Norte no hemos detectado diferencias en las técnicas y en la calidad constructiva de los distintos edificios, ni entre los complejos residenciales. Sin embargo, y como explico más adelante, en varios casos fue difícil definir los límites de dichos complejos y, por lo tanto, el número de estructuras de cada uno. En conclusión, los estudios que actualmente estamos realizando sobre la arquitectura doméstica de sitios tardíos del valle Calchaquí Norte señalan preliminarmente la similitud formal y arquitectónica de los complejos residenciales. Asimismo, otros estudios sobre la arquitectura y la organización espacial de sitios tardíos han notado este mismo patrón, especialmente en sitios como Ruiz de los Llanos y Buena Vista (DeMarrais 1997) y Tero (Díaz 1978-1980 Ms). Esto parece también tener lugar en varios sitios de la Puna de Jujuy. En Pueblo Viejo de Tucute la arquitectura doméstica es uniforme, a excepción de dos complejos residenciales que apenas se diferencian del resto, uno por tener muros revocados con arcilla roja y el otro por la presencia de un gran deflector monolítico con grabados de llamas. En este caso, debemos plantearnos, al igual que quienes investigaron el sitio (Albeck 2001) si

(1969) y Cremonte (1992) para el Pucara de Tilcara preincaico; Cigliano (1973) para Tastil y Raffino (1972) para Morohuasi en la quebrada del Toro; y Baldini (1992) para Molinos I en el valle Calchaquí Medio. Nuestras propias investigaciones en el valle Calchaquí Norte están detectando también este aspecto en sitios como La Paya, Las Pailas y Mariscal. estos rasgos por sí solos fueron un signo de mayor estatus. En Doncellas, los complejos residenciales tampoco parecen diferenciarse unos de otros, inclusive varios presentan menhires cilíndricos de piedra en sus muros (Alfaro y Suetta 1976; Alfaro 1983). La arquitectura doméstica es también similar en Pueblo Viejo de Potrero y en Ojo de Agua (Albeck et al. 1999, 2001; Dip 2001), así como en el Pucara de Rinconada (Alfaro y Suetta 1970; Albeck 2001). En varios sitios de la quebrada de Humahuaca se destaca la considerable homogeneidad en el trazado de los ámbitos domésticos, tal como en Juella (Nielsen et al. 2004), Volcán (Garay 1998), el Pucara de Yacoraite (Krapovickas 1969), La Huerta (Palma 1997-1998; Leibowicz 2006) y el Pucara de Tilcara preincaicos (Casanova 1958). Los Amarillos merece un párrafo aparte.

En efecto, arquitectónicamente el sitio es homogéneo, con excepción del Complejo A, que presenta una técnica constructiva marcadamente distinta producto de la influencia incaica (Nielsen y Walker 1999; Nielsen 2001). Recientemente, un sector del sitio ha sido detalladamente estudiado (Taboada y Angiorama 2003a, 2003b; Angiorama 2005), pudiéndose establecer la recurrencia de un patrón arquitectónico compuesto por complejos residenciales de un recinto mayor y uno o dos recintos menores, siendo la arquitectura de estos complejos similar, así como su tamaño. Sin embargo, en este asentamiento existen diferencias en las alturas en las que se emplazan los complejos residenciales, lo que habría generado asimetrías en las vistas accesibles desde uno u otro lugar. Los Amarillos es un sitio de estructuras aglomeradas, con diferentes nucleamientos de recintos separados por cauces secos y algo profundos que configuran una topografía con pendientes y estructuras ubicadas a distintas alturas. Los cauces dibujan anfiteatros naturales con sectores deprimidos y otros elevados en donde se construyeron y estructuras de distintas formas y tamaños. Aquellas que están más cerca de los cauces se encuentran topográficamente más bajas que las que están más alejadas. Estas aglomeraciones ofrecen en un espacio reducido estructuras a diferente nivel y otras enfrentadas al mismo nivel, pero de un lado y otro de los cauces. El diseño espacial del sitio y la topografía creaban asimetrías visuales, que han sido destacadas como indicadores de desigualdad y estratificación. Estas asimetrías en las vistas tuvieron lugar en el Complejo A, por lo que se lo ha considerado un sector de élite (Nielsen 1995). La posición topográfica más alta de este conjunto restringía el acceso visual de los que estaban más 
abajo. Se debe destacar que este no es el único caso en Los Amarillos, sino que existen otros conjuntos arquitectónicos en condiciones similares al del Complejo A. Además, y si bien desde los recintos más elevados se podía tener una mejor vista de lo que hacía la gente de más abajo o de enfrente, mientras que desde los edificios de la parte más deprimida se tenía menor campo de visión, el aglomeramiento y la disposición de los recintos en estos anfiteatros no restringía la percepción de lo que sucedía en el entorno a través de otros sentidos. La aglomeración y la topografía debieron haber facilitado escuchar y oler a los de otros sectores, y por lo tanto conocer lo que ocurría en la comunidad.

En Tastil las técnicas arquitectónicas empleadas en el sitio son las mismas. Posee dos tipos de complejos residenciales: simples (o de un solo recinto) y compuestos (Cigliano 1973; Cigliano y Raffino 1973). Si bien la mayoría de los complejos son compuestos, al este del sitio se emplazaron de forma aglutinada recintos que, al parecer, no estaban articulados entre sí. Esta división en dos no demuestra estratificación, sino quizá diferencias funcionales. En El Pichao, la arquitectura residencial es uniforme y de tamaño similar (Bengtsson 2001a, 2001b; Stenborg 2001; Cornell y Fahlander 2002), y el patrón de asentamiento bastante homogéneo, no exhibiendo rastros de jerarquización espacial (Bengtsson 2001a; Stenborg 2001). Una situación similar parece haber tenido lugar en Molinos I en el valle Calchaquí Medio (Baldini 1992). Sin embargo, más al sur la situación podría haber sido distinta, ya que en Rincón Chico existen estructuras que pudieron haber pertenecido a la élite del asentamiento, puesto que se localizan en un sector residencial en la cumbre de un cerro y asociadas a posibles espacios públicos (Tarragó 1995, 2000).

En quinto lugar, y si bien este es un aspecto que necesita mayor investigación, los artefactos se encuentran uniformemente distribuidos en los sitios tardíos, no habiendo indicadores claros de control y acumulación de bienes por parte de unidades domésticas o grupos dentro de las comunidades que habitaban estos grandes poblados conglomerados. Consecuentemente, no habrían existido marcadas diferencias respecto a los bienes consumidos o empleados dentro de los complejos residenciales. Todos los residentes de un poblado usaban los mismos tipos de objetos y contaban con similares herramientas y medios de producción. Es común encontrar dentro de las viviendas restos de vasijas cerámicas decoradas y sin decorar de distintas formas y tamaños, instrumentos para la producción textil (torteras y husos), para el procesamiento de recursos vegetales (manos, conas y morteros), para la producción metalúrgica (moldes, crisoles, minerales), para la producción cerámica (arcillas, antiplásticos y pigmentos), para las tareas agrícolas (azadas y palas), así como otras herramientas y materia prima necesaria para su producción, como líticos locales y foráneos. En el valle Calchaquí Norte, he seleccionado al azar 20\% de los complejos residenciales del sitio Mariscal, los cuales han sido objeto de estudios de superficie (arquitectónicos, espaciales y del material de superficie), detectándose los mismos tipos de artefactos: cerámica decorada y sin decorar, artefactos y materia prima lítica, obsidiana $\mathrm{y}$ artefactos de molienda. Excavaciones parciales en dos de dichos complejos residenciales confirman lo anterior, y lo mismo parece ocurrir en otros sitios de la región, como Borgatta (DeMarrais 1997) ${ }^{15}$, Tero (Díaz 1978-1980 Ms) y Valdez (D’Altroy et al. 2000). Similares tipos de artefactos fueron depositados en las tumbas excavadas por Ambrosetti (1907-1908), al menos aquellas que no muestran influencia incaica. Incluso varios objetos de metal (cinceles, pinzas, hachuelas y punzones) estuvieron ampliamente distribuidos, incluyendo pequeñas placas de cobre. Una situación similar podría haber ocurrido en asentamientos de otras regiones, como en Doncellas, en la Puna de Jujuy (Ottonello 1973; Alfaro y Suetta 1976); Los Amarillos (Angiorama 2005), La Huerta (Palma 2000; Leibowicz 2006), Juella (Nielsen et al. 2004) y el Pucara de Tilcara (Madrazo 1969) en la quebrada de Humahuaca; y en El Pichao, en el norte del valle de Yocavil (Cornell 1993; Bengtsson 2001a; Cornell y Stenborg 2001; Sjödin 2001; Stenborg 2001), verificándose claramente en Tastil, donde las excavaciones en varios

15 Sin embargo, esta investigadora parece forzar la evidencia para adecuarla con su búsqueda de jefaturas. A partir del análisis del material de superficie afirma haber encontrado una unidad residencial con más fragmentos de escudillas decoradas que el resto $(1997,2001)$. De acuerdo con el modelo de jefatura que sigue, las escudillas habrían sido empleadas por las élites para servir y redistribuir comida en contextos ceremoniales auspiciados por los jefes, con el fin de adquirir adeptos y acumular poder. DeMarrais considera que esta aparente acumulación de escudillas probaría que los habitantes de esta unidad residencial constituían una élite que monopolizaba el uso de ciertos ítems materiales para obtener el control de algunas prácticas claves para la reproducción social. No obstante, la diferencia en la distribución de restos de escudillas entre las unidades residenciales que presenta es mínima y no es estadísticamente significativa. Sumado a esto, no ofrece evidencia arquitectónica del complejo residencial con más escudillas para demostrar que era la vivienda de una élite separada y diferenciada del resto. 
recintos habitacionales demostraron que distintos tipos de bienes y herramientas de producción se encontraban uniformemente distribuidos entre sus habitantes (Cigliano 1973). La cerámica local está homogéneamente distribuida, al igual que algunos tipos foráneos, como los vasos puneños (Cigliano y Calandra 1973). Otros tipos cerámicos foráneos también tienen una amplia distribución en el sitio (especialmente en las tumbas), y aparecen en una variedad de contextos, como habitaciones, basureros y tumbas (Cigliano 1973; Cigliano y Calandra 1973). Relacionado a lo anterior, las evidencias señalan que los complejos residenciales fueron el foco de una amplia variedad de actividades (producción, almacenaje, procesamiento y consumo de alimentos, producción y uso de artefactos, prácticas rituales, reproducción social, entre otras) y que las mismas no variaban significativamente entre las distintas unidades domésticas que habitaban un mismo asentamiento. Por lo tanto, se puede afirmar que no existía una marcada división del trabajo y que la esfera doméstica fue el centro de muchas prácticas claves en la vida social de las comunidades del Tardío.

\section{Vida cotidiana y experiencias en los poblados conglomerados: Hacia una nueva interpretación del Período Tardío del Noroeste Argentino}

Se ha señalado que un rasgo destacado del Período Tardío fue la tendencia a localizar los asentamientos en lugares elevados que beneficiaban su defensa, lo que indicaría que el conflicto entre regiones y comunidades fue frecuente (Tarragó 2000). Los centros más importantes de la mayoría de las regiones del N.O.A. fueron poblados extensos y conglomerados (ver sector B en Figura 2, ver también figuras 3 y 4). Esta aglomeración de los edificios pudo haber sido causada por la posición elevada que los poblados ocuparon en el paisaje, en lugares defensivos aunque de escasa superficie. Sin embargo, muchos de los grandes centros del período no presentan rasgos defensivos y se emplazaron en los fondos de valle o en amplias terrazas o piedemontes cercanos a los fondos de valle y a los campos agrícolas (Raffino 1988: 163-164), donde había más lugar para construir. En estos casos, y a pesar de la disponibilidad de espacio, las comunidades tardías eligieron un patrón celular concentrado para asentar sus viviendas y edificios. Se puede suponer entonces que si bien el conflicto pudo en principio haber empujado a las personas a vivir más cerca unas de otras que en períodos previos, en algún momento del período, construir poblados con estructuras aglomeradas se convirtió en la manera normal y establecida de habitar. Entre éstos, los más destacados son Doncellas, Pueblo Viejo de Potrero, Ojo de Agua, Pucara de Rinconada y Pueblo Viejo de Tucute en la Puna de Jujuy; Los Amarillos, Pucara de Yacoraite, Campo Morado, La Huerta, Pucara de Tilcara, Juella y Pucara de Volcán en la quebrada de Humahuaca; Tastil y Morohuasi en la quebrada del Toro; Valdez, Mariscal, Borgatta, Las Pailas, Corral el Algarrobal, Loma del Oratorio y La Paya, entre otros, en el valle Calchaquí Norte; Molinos I y El Churcal en el valle Calchaquí Medio; Loma Rica de Shiquimil y ciertos sectores de Tolombón, El Pichao, Quilmes, Fuerte Quemado y Rincón Chico, entre otros, en el sur del valle Calchaquí y en el valle de Yocavil.

Ahora bien, ¿cómo era vivir en uno de estos asentamientos tardíos?, ¿cómo se estructuraban las relaciones sociales?, ¿qué tipo de experiencias se vivían?, ¿qué se percibía diariamente?, ¿qué tipo de habitus (sensu Bourdieu 1977, 1999) generaba la experiencia en estos centros?, ¿qué aspectos estructurales se incorporaban y corporizaban a través de las rutinas diarias?, ¿qué tipos de experiencias, percepciones y relaciones sociales cotidianas propiciaban el diseño espacial de los asentamientos conglomerados, y cuáles clausuraban?

Como he explicado, en regiones como la Puna de Jujuy, la quebrada de Humahuaca, la quebrada del Toro y el valle Calchaquí Norte y Medio, los grandes asentamientos de la época no estaban fragmentados y divididos en sectores jerárquicamente diferentes, sino que se constituyeron como extensos campos de estructuras articuladas entre sí. Estaban formados por complejos residenciales aglomerados, siendo la residencia doméstica la unidad arquitectónica básica en la organización espacial de estos asentamientos. No se han detectado edificios de instituciones que indiquen centralización política, y los asentamientos no parecen haber crecido a partir de un edificio particular o espacio público central, no existiendo una estructura que haya actuado como polo de atracción del resto. Más bien, los grandes poblados tardíos se desarrollaron a partir de la acumulación de complejos residenciales y algunos espacios abiertos no formalizados intercalados, todos de arquitectura similar en cuanto a estilo, técnicas y calidad constructiva, y emplazados unos al lado de los otros, dando lugar a un patrón celular. Las viviendas de estos grandes 


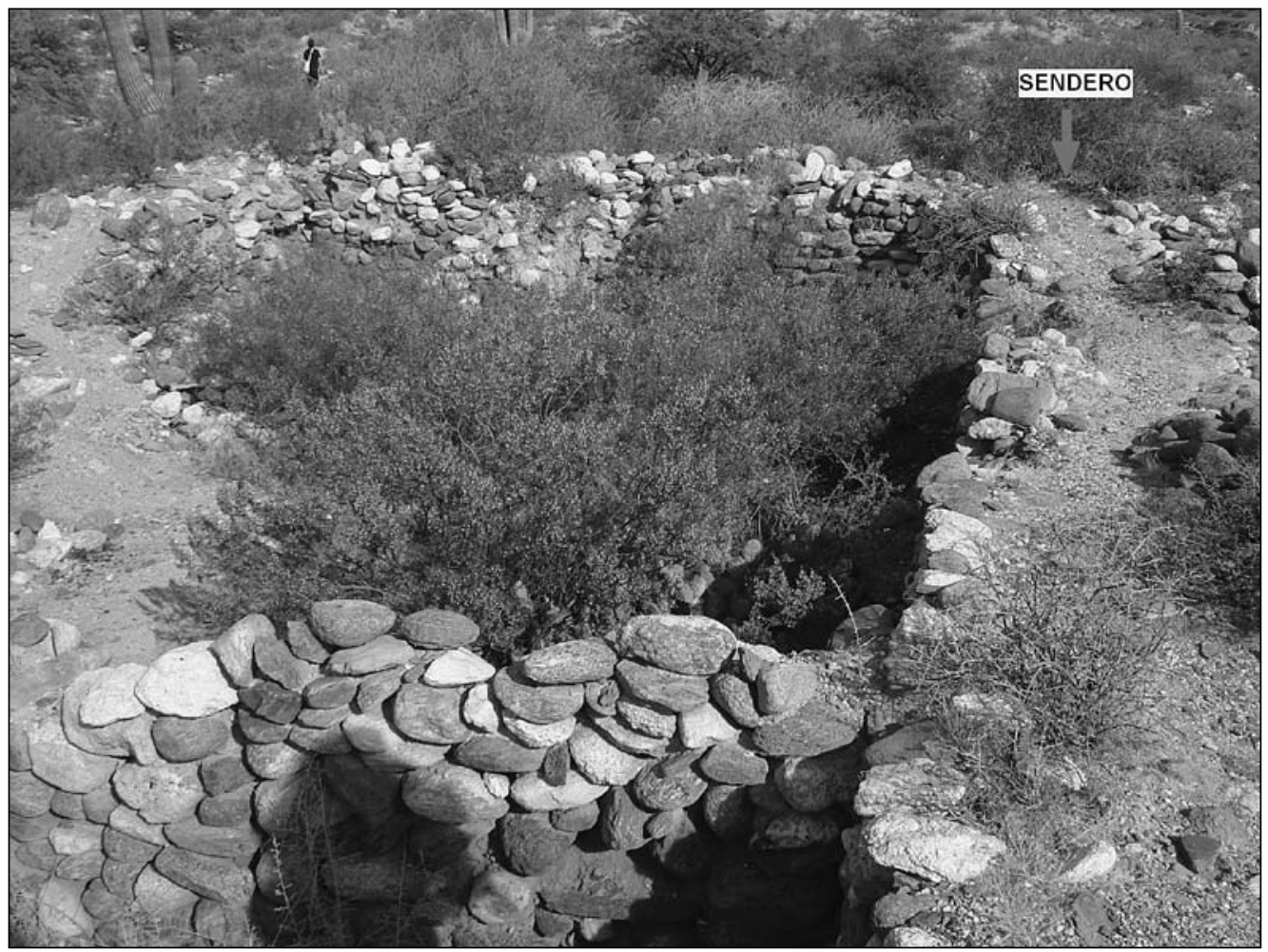

Figura 5. Sendero interno y entre recintos en La Paya, valle Calchaquí Norte.

poblados compartían muros, pasillos y pasajes, y en varios casos fueron semisubterráneas (Raffino 1988: 175, 176). Calzadas especialmente diseñadas (en algunos casos artificialmente sobreelevadas) y los anchos muros de las numerosas estructuras sin techo creaban redes de senderos internos que serpenteaban a través de los asentamientos y permitían la circulación entre y por arriba de los edificios (Figuras 4 y 5). En otros casos, la falta de estas calzadas hace suponer que para acceder a recintos internos se debía pasar de estructura en estructura (ver Figura 2). Hay incluso casos donde los senderos penetran y atraviesan el interior de los complejos residenciales (Alfaro y Suetta 1970; Albeck et al. 1999; Taboada y Angiorama 2003a, 2003b), de manera que circular implicaba pasar entre los diferentes complejos residenciales. Por ejemplo, en el valle Calchaquí Norte, el estudio de la forma de circulación interna determinó que en Mariscal existe un sendero que recorre el lado oeste del sitio $y$ un posible sendero que recorre el lado este, ambos entre las estructuras y la barranca. También, reconocimos tramos de un sendero interno que circula por arriba de los recintos semisubterráneos. En algunas partes, dicho sendero se corta para articularse con los muros de estructuras, para volver a aparecer en otro sector del sitio. De esta manera, la circulación interna se realizó a través de sendas y por sobre los muros anchos (de hasta $1 \mathrm{~m}$ ) de los recintos más grandes. La utilización de los muros como vías de circulación produjo la ramificación de los senderos sobre la superficie del sitio.

La organización espacial y la arquitectura de los poblados tardíos ponían en proximidad física a sus habitantes, que gracias a la conglomeración de estructuras podían oír las conversaciones de los vecinos más cercanos o reconocer auditivamente el tipo de actividades que estaban realizando (p.e., tallar artefactos líticos, moler granos o cortar leña). Debió haber sido también fácilmente perceptible el olor de lo que otros estaban cocinando o quemando, ya que las paredes, o la gran cantidad de estructuras sin techo ${ }^{16}$, hacían permeable los sonidos y los

16 Raffino y Alvis (1993) calculan que el 46\% de las estructuras de La Huerta no fueron techadas. En muchas excavaciones de recintos en sitios tardíos, especialmente en recintos de grandes dimensiones, no se encontraron evidencias de techado (Casanova 1958; Cigliano 1973; Alfaro 1983). 
olores. La cercanía entre las residencias permitía a los miembros de una comunidad conocer lo que los otros hacían o hablaban, lo que también fue facilitado por la circulación a través del asentamiento. Al caminar por los senderos sobreelevados o por arriba de los anchos muros, o al circular pasando de recinto en recinto, los habitantes de estos asentamientos se encontraban con su comunidad, pudiendo ver lo que otros hacían en sus residencias, especialmente en los grandes patios abiertos y las amplias habitaciones sin techo, donde, por cuestiones de temperatura, luz, espacio y ventilación, la mayoría de las actividades eran efectuadas. ${ }^{17}$ La circulación dentro de estos sitios de estructuras aglomeradas producía la constante interacción de la gente y las familias, permitiendo a las personas ver las actividades que los otros residentes desarrollaban, los bienes que consumían o los rituales que realizaban. Aunque quizá hubo restricciones simbólicas a la circulación, ciertamente no hubo limitaciones materiales.

De este modo, la espacialidad y la materialidad de estos asentamientos no producían una comunidad fragmentada, sino articulada y aparentemente homogénea. El diseño espacial y material de los grandes poblados tardíos, más que separar a las personas, las acercaba. ${ }^{18}$ Vivir en un asentamiento tardío implicaba compartir paredes, espacios, sendas y, ya sea explícitamente o porque quedaban al alcance de las percepciones, experiencias. El hecho de que las actividades que se realizaban en las distintas residencias fueran aproximadamente similares indica que también se compartían conocimientos básicos para el desarrollo de la vida cotidiana (pe., sobre técnicas constructivas, producción de artefactos, producción primaria, formas de organizar el espacio, etc.). Y el hecho de que

17 Hay actividades que necesitan insolación y ventilación, y que por lo tanto es mejor que se realicen al aire libre, tal como el secado de productos alimenticios, la metalurgia y la curtiembre. Además, el techado de un recinto requería de una gran inversión de trabajo para conseguir los elementos y para realizarlo. En los sitios del valle de Yocavil, aunque no en otros lugares, se encontraron evidencias de galerías construidas en los bordes de los patios, aunque no en todo el perímetro, sino sólo en alguno de sus lados (Raffino 1988).

18 Loma Rica de Shiquimil es un sitio conglomerado alargado de 189 recintos entre habitaciones y patios, con dos plazas hacia el este y 15 espacios de circulación y un sendero norte-sur que segmenta al sitio en dos. Entre todas estas estructuras hay sólo nueve conjuntos articulados (Tarragó 1995), lo que demuestra la gran interconexión de los recintos. todos consumiesen o empleasen objetos similares y una misma iconografía señala que también se compartía una identidad común, de modo que el ethos que se experimentaba estaba más ligado a una ideología de compartir, articular e integrar, que a una de dividir o segregar.

Aunque aún se necesita más investigación sobre las formas y límites de los complejos residenciales, la existencia de grupos de recintos no asociados a patios, o la presencia de grandes estructuras (o conjuntos asociados de grandes estructuras) comunicadas con varios complejos residenciales o con ninguno en especial, sugiere que las grandes estructuras $o$ espacios abiertos eran compartidos por los miembros de distintos complejos residenciales. Por ejemplo, en las investigaciones en Mariscal no siempre pudimos encontrar los "clásicos" complejos residenciales del Tardío del N.O.A. compuestos por un patio abierto asociado a dos o tres recintos habitacionales, sino que hay casos de recintos habitacionales no asociados a patios (ver Figura 3, conjunto A), o grupos de tres o cuatro patios articulados y no asociados directamente a recintos habitacionales (ver Figura 3 , conjunto B).

Es posible entonces, que distintas unidades domésticas hayan usado en conjunto un espacio abierto o patios donde se congregaban para desarrollar actividades grupales. Estos espacios mayores no articulados directamente con los recintos habitacionales o comunicados al mismo tiempo con varias residencias, pudieron haber sido lugares de uso colectivo y socialización que superaban los límites de la unidad doméstica. Esto demostraría la permeabilidad entre los distintos complejos residenciales, no pudiéndose determinar con claridad los límites entre unos y otros. Solemos transferir nuestro modelo occidental de unidad doméstica al pasado, buscando por lo tanto residencias individuales y autocontenidas para cada unidad doméstica, sin embargo, los límites entre los complejos residenciales en los sitios del Período Tardío son a veces borrosos y, por lo tanto, la forma de concebir el ámbito doméstico no incluía una preocupación estrecha por la privacidad. Así, los límites entre las residencias, entre lo público y lo privado, entre la unidad doméstica y la comunidad, fueron flexibles y permeables. ${ }^{19}$

\footnotetext{
19 A través de un sofisticado análisis arquitectónico de un sitio tardío de Lípez (Bolivia), Vaquer (2006 Ms) demuestra este punto.
} 
Relacionado con esto, cabe destacar las evidencias de actividades comunales de molienda que aparecen en varios sitios, como recintos que acumulan artefactos de molienda o afloramientos de roca que agrupan morteros (Raffino 1972, 1988; Cigliano y Raffino 1973; Tarragó 1987; Cornell 1993; Nastri 1997-1998; Sempé 1999; Williams 2003), así como la combinación de actividades de molienda grupales y almacenaje no centralizado, sino que realizado a nivel doméstico (Raffino 1988). La falta de evidencias que indiquen que la producción comunal era capturada para el usufructo de unos pocos señala que la actividad de molienda conjunta no era producto de mano de obra movilizada y explotada, sino que era una práctica voluntaria que constituyó otra esfera de experiencia comunal, donde posiblemente se compartían historias, noticias y experiencias. La combinación de almacenaje doméstico y actividades de producción compartidas pudo haber tenido una fuerte carga ideológica. En estos casos, los recursos salen del trabajo comunal y se dirigen a las familias individuales, lo que genera la sensación de que es la comunidad quien provee, cuida y alimenta a los suyos.

Para el valle Calchaquí Norte tenemos un dato interesante: las ollas de cocina recuperadas de varios sitios son de grandes dimensiones, llegando a tener $80 \mathrm{~cm}$ de alto y un diámetro de hasta $60 \mathrm{~cm}$. Prácticamente no se han encontrado ollas de cocina pequeñas. Esto indicaría que se cocinaba para un gran número de gente y no sólo para los integrantes de la familia nuclear, siendo posible que varias personas participaran en las comidas, compartiendo los alimentos cocinados. La alimentación constituía así otra esfera de integración.

Un aspecto importante sobre las experiencias que se vivían en un asentamiento del Período Tardío fue la homogeneidad material. En estos poblados, todos residían en viviendas de diseño, formas y técnicas constructivas similares, empleaban los mismos tipos de artefactos, aplicaban las mismas técnicas y motivos para decorar los objetos y consumían bienes similares. Al circular por estos asentamientos, visitar a vecinos o participar de actividades comunales, las personas podían percibir la redundancia material, experimentando un paisaje material uniforme y repetido que debió haber contribuido a establecer un sentido de semejanza, donde cada familia o grupo era el reflejo del otro.
Se puede argumentar entonces que el diseño espacial de los poblados tardíos promovía la interacción cotidiana de sus residentes. Al habitarlos, las personas no se topaban con sectores a los que no podían acceder, con construcciones monumentales que superaban y minimizaban la escala humana o con edificios que representaban un poder coercitivo. Las prácticas e interacciones en estos poblados no tenían lugar en un ambiente de límites rígidos y que generaba segregación, sino que se desarrollaban en una espacialidad y materialidad que física y simbólicamente propiciaban la permeabilidad y la integración comunal. ${ }^{20}$ Muchas actividades y relaciones se daban ante los ojos (y otros sentidos) de la comunidad. Consecuentemente, la privacidad no fue una preocupación central.

La circulación parece haber sido un modo central de socialización y una manera de obtener un conocimiento estrecho de la comunidad propia. Lo que la gente observaba al circular no eran áreas del asentamiento que estaban materialmente restringidas, edificios localizados aparte del resto, gente empleando o consumiendo otras clases de bienes, familias habitando viviendas mejor construidas, o la infraestructura de un poder político. Al contrario, se experimentaba un paisaje materialmente homogéneo y que propiciaba redes de comunicación ( $\mathrm{y}$ posiblemente solidaridad) intracomunales, lo que debe haber creado un sentido de lugar caracterizado por un sentimiento de integración comunal y de ausencia de diferenciación social. La materialidad y espacialidad que caracterizaba a la vida social del Período Tardío propiciaba una ideología de igualdad material y similitud, más que de estratificación, que era corporizada por quienes allí habitaban a partir del desarrollo de prácticas e interacciones en estos escenarios.

El diseño espacial promovía el encuentro constante de los miembros de la comunidad y el reconocimiento de las prácticas que cada cual realizaba. La aglomeración posibilitó a la gente ver lo que cada unidad doméstica hacía, así como también oler o escuchar la actividades de los vecinos. Dentro de estos asentamientos conglomerados muchas experiencias, como rituales, producción y consumo de bienes,

20 Muchos sitios de este período tienen muro perimetral. En muchos casos, estos muros no tuvieron funciones defensivas, ya que los sitios no se encuentran en lugares fáciles de proteger, por lo cual se puede pensar que era una forma de definir a la comunidad. 
prácticas mortuorias y ocio, fueron compartidas y notorias, lo cual implicó un alto grado de control comunal por consenso, siendo la acumulación de poder y beneficios materiales muy evidentes y fáciles de regular y restringir. Así, la comunidad podía limitar y controlar los intentos por obtener beneficios y acumular poder.

El incremento en el conflicto que comenzó a darse en el período llevó a las comunidades a habitar en lugares estratégicos donde el espacio era escaso y a residir en asentamientos conglomerados, modalidad que en algún momento se constituyó en la forma normal de habitar. Fue justamente esta forma de habitar la que, al menos en parte, generó una vida social caracterizada por la integración comunal y donde las tendencias a la desigualdad y a la acumulación de poder se vieron limitadas. Dentro de los poblados tardíos la gente compartía experiencias, espacios, muros, sonidos, olores, objetos y símbolos. No había gente viviendo apartada de los demás, con mejores complejos residenciales, con acceso a arquitectura monumental y control sobre el excedente de producción, consumiendo bienes diferentes o utilizando otro tipo de herramientas y tecnología. Los conocimientos eran compartidos y al parecer no eran utilizados como fuente de poder, experimentándose así un sentido de homogeneidad, articulación y permeabilidad.

Esta ideología de igualdad material e integración que se vivía en los poblados, producida y reificada por el mundo material y la espacialidad en las que las personas habitaban, no necesariamente debió implicar su plena aceptación o la inexistencia de contradicciones o acciones orientadas a desafiarla y superarla. La misma experiencia de habitar en estos lugares debió generar al mismo tiempo reivindicaciones y rechazo de este ethos de integración comunal. El mundo social y material creado en los poblados conglomerados encarnaba una ideología que intentaba controlar y limitar contradicciones, que sin dudas existían, que tendían a fracturar las comunidades y a crear distinción y desigualdad. Como claramente se ha establecido, el Período Tardío fue una época de conflictos e incremento del contacto e intercambio interregional (Nielsen 1996, 2001; Tarragó 2000). Posiblemente las oportunidades para obtener prestigio y poder que daban las actividades bélicas, así como las oportunidades para crear distinción que el intercambio y el acceso a nuevos bienes, información y conocimientos podían generar, crearon presiones sobre esta ideología de integración e igualdad material. Así, el mundo social que se experimentaba dentro de los poblados pudo haber estado en tensión y contradicción con aquel que se vivía fuera del mismo. Incluso en su interior la preservación de la integración comunal pudo haber estado en tensión con intentos por acumular poder y prestigio. La evidencia arqueológica sugiere que también hubo dentro de estos asentamientos competencia por poder y prestigio ya que la presencia de más de un espacio abierto o estructuras de posible uso público o ritual ubicadas en distintas partes de un sitio sugiere que diferentes grupos, facciones políticas o familias extensas pudieron haber llevado a cabo fiestas redistributivas para ganar adeptos y seguidores, y así obtener poder y prestigio. De este modo, la integración comunal pudo haber estado constantemente en tensión y contradicción con prácticas que propiciaban la estratificación y la desigualdad. Sin embargo, durante el Período Tardío éstas estaban aún lejos de ser aspectos institucionales de la vida social de la época. La concentración poblacional, que pudo haberse iniciado a partir del incremento de las situaciones de conflicto, no llevó, como generalmente se propone, a la complejidad social debido a la necesidad de organizar y controlar a un número mayor de gente. Al contrario, habitar poblados conglomerados generó una dinámica social caracterizada por fluidas relaciones sociales, permeabilidad y estrecho conocimiento de la propia comunidad. El sentido de lugar experimentado en estos asentamientos no era de segregación y desigualdad, sino que estuvo más cercano a la integración comunal.

No obstante, esta situación no parece haber estado difundida en todo el N.O.A. En regiones del sur, como el sur del valle Calchaquí, el valle de Yocavil y el centro y sur de la provincia de Catamarca, la vida cotidiana no tenía lugar en poblados conglomerados y homogéneos, sino que muchos de sus principales asentamientos estaban constituidos por sectores separados y jerárquica y funcionalmente diferenciados (Tarragó 1987, 1995; Nastri 1999; Sempé 1999). En estas regiones la mayoría de los sitios se caracterizan por la ausencia del aglutinamiento urbano (Raffino 1988), no compartiéndose muros, espacios, actividades o conocimientos; los edificios no estaban necesariamente articulados y la circulación interna no integraba las distintas partes del sitio. Además, habría existido una distribución desigual de los bienes (Tarragó y González 1996; Tarragó y Nastri 1999). Esta diferencia entre, a grandes rasgos, el área norte y sur del N.O.A., puede ser producto de trayectorias históricas diferentes, 
ya que en el área sur los procesos de desigualdad y estratificación habrían tenido mayor profundidad temporal debido al fenómeno de Aguada.

\section{Conclusiones}

He intentado realizar una reinterpretación del Período Tardío del Noroeste Argentino a partir de un cambio de enfoque teórico-metodológico. Propuse dejar de lado las perspectivas objetivistas usualmente empleadas para analizar el período, apoyadas en acercamientos evolucionistas y funcionalistas, para poner énfasis en las prácticas, experiencias y relaciones sociales que tenían lugar en el transcurrir diario de la vida social. Se pasó de este modo, de lo macro a lo micro; de explorar aspectos estructurales (especialmente relacionados con la caracterización de la escala de organización sociopolítica), a estudiar la vida social tomando como entrada la naturaleza de la vida cotidiana.

Para esto, se dejó de considerar a los objetos y formas espaciales como productos neutrales y estáticos de la organización social, y de examinar a los sitios (a través de perspectivas "a vuelo de pájaro" y que superan la escala humana) como reflejos pasivos de procesos sociales de mayor escala, para pasar a investigar el tipo de vida social que espacialidades (histórica y culturalmente específicas) recursivamente creaban y reproducían. De este modo, un sitio arqueológico no fue considerado simplemente como un punto en el espacio, sino más bien como un lugar que creaba una red de relaciones específicas entre materialidad, gente, significados e historia. Se buscó así repoblar el pasado, reflexionando sobre los sitios a través de las prácticas, experiencias y relaciones que la espacialidad y materialidad de los poblados del Período Tardío creaban y articulaban cotidianamente, así como también limitaban o restringían.
A través de este enfoque y de la revaluación crítica de las evidencias se argumentó que en regiones como la Puna de Jujuy, la quebrada de Humahuaca, la quebrada del Toro y el valle Calchaquí Norte y Medio, la vida social en el Período Tardío, producto de una forma particular de habitar, estuvo más relacionada con la integración comunal y la homogeneidad simbólica y material, que con una organización sociopolítica caracterizada por la centralización, la desigualdad y la estratificación institucionalizadas. No obstante, esto no implicó la ausencia de conflictos y contradicciones. El sentido de integración, permeabilidad y de no segregación y fragmentación social que se experimentaba en los asentamientos, pudo haber estado en tensión con luchas por superar los constreñimientos estructurales y obtener poder y jerarquía, posiblemente generadas por las oportunidades que daban los crecientes conflictos e intercambios interregionales que en esta época habrían tenido lugar. Sin embargo, en regiones de más al sur, como el valle de Yocavil y el centro y sur de la provincia de Catamarca, la situación fue diferente y sí habría involucrado procesos de desigualdad y estratificación, posiblemente producto de una trayectoria histórica distinta.

En sintonía con las tendencias en teoría social de las últimas décadas, intenté mostrar que un entendimiento más profundo y detallado de la dinámica social se logra al analizar las acciones, prácticas y relaciones sociales, y su contingencia histórica. Como nos han enseñado la historia, la etnografía y la sociología, la complejidad de estas últimas supera ampliamente las generalidades que una descripción objetivista de la sociedad suele ofrecer.

Agradecimientos A Jorge Palma, Clara Rivolta, Iván Leibowicz y Cristian Jacob por sus útiles comentarios.

\section{REFERENCIAS CITADAS}

ACUTO, F. A., 1999. Paisaje y dominación: La constitución del espacio social en el Imperio Inca. En Sed non satiata. Teoría social en la arqueología latinoamericana contemporánea, A. Zarankin y F. Acuto (Eds.), pp. 33-75. Ediciones del Tridente, Buenos Aires.

2004. Landscapes of ideology and inequality: Experiencing Inka domination. Ph. D. Dissertation, State University of New York, Binghamton.

ALBECK, M. E., 1997. Areas de actividad doméstica en Pueblo Viejo de Tucute. Estudios Atacameños 12: 69-81.
2001. La Puna Argentina en los períodos Medio y Tardío. En Historia prehispánica argentina, vol. 1, E. Berberián y A. Nielsen (Eds.), pp. 347-388. Editorial Brujas, Córdoba.

ALBECK, M. E., S. DIP y M. ZABURLIN, 1998. El patrón arquitectónico de Pueblo Viejo de Tucute. En Los desarrollos locales y sus territorios. Arqueología del N.O.A. y sur de Bolivia, M. B. Cremonte (Ed.), pp. 223-244, Universidad Nacional de Jujuy, San Salvador de Jujuy.

2001. La organización del espacio en poblados del Tardío de Casabindo, Puna de Jujuy. Actas del XIII Congreso Nacional de Arqueología Argentina, vol. 1, pp. 395-408. Córdoba. 
ALBECK, M. E., M. ZABURLIN y S. DIP, 1999. Etnicidad y arquitectura doméstica en Casabindo. Actas del XII Congreso Nacional de Arqueología Argentina, vol. 2, pp. 211-220. La Plata.

ALFARO, L., 1983. Investigaciones arqueológicas en la cuenca del río Doncellas (provincia de Jujuy). Integración de la Puna Jujeña a los centros cúlticos andinos. Relaciones de la Sociedad Argentina de Antropología N. S. 15: 25-47.

ALFARO, L. y J. M. SUETTA, 1970. Nuevos aportes al estudio del asentamiento humano en la Puna de Jujuy. Revisión del Pucara de Rinconada. Antiquitas X: 1-10.

1976. Excavación en la cuenca del río Doncellas. Antiquitas XXII-XXIII: 1-32.

AMBROSETTI, J. B., 1907-1908. Exploraciones arqueológicas en la ciudad prehistórica de La Paya (valle Calchaquí, provincia de Salta). Universidad de Buenos Aires, Buenos Aires.

ANGIORAMA, C., 2001. La producción prehispánica de objetos metálicos en la quebrada de Humahuaca (Jujuy). Actas del XIII Congreso Nacional de Arqueología Argentina, vol. 1, pp. 35-42. Córdoba.

2005. Nuevas evidencias de actividades metalúrgicas prehispánicas en la quebrada de Humahuaca (Jujuy, Argentina). Anales del Museo de América 13: 173-198.

BALDINI, L., 1992. El sitio Molinos I dentro de los esquemas de desarrollo cultural del Noroeste Argentino. Arqueología, Revista de la Sección Arqueología 2: 53-68.

BENDER, B., 1993. Introduction: Landscape: Meaning and action. En Landscapes: Politics and perspectives, B. Bender (Ed.), pp. 1-17. Berg Publishers Ltd., Oxford.

BENDER, B., S. HAMILTON y C. TILLEY, 1997. Leskernick. Stone worlds; alternative narratives; nested landscapes. Proceedings of the Prehistoric Society 63: 147-178.

BENGTSSON, L., 2001a. A comparison of architectural remains at the Pichao, Tolombón and Tallapazo sites of the Santa María culture in Northwestern Argentina. En Investigations at Pichao. Introduction to studies in the Santa María Valley, Northwestern Argentina, L. Bengtsson, P. Cornell, N. Johansson y S. Sjödin (Eds.), pp. 33-46. BAR 978, Oxford.

2001b. The perception and notion of space in relation to architecture. En Investigations at Pichao. Introduction to studies in the Santa María Valley, Northwestern Argentina, L. Bengtsson, P. Cornell, N. Johansson y S. Sjödin (Eds.), pp. 19-32. BAR 978, Oxford.

BOURDIEU, P., 1977. Outline of a theory of practice. Cambridge University Press, Cambridge.

-1999. Meditaciones pascalianas. Editorial Anagrama, Barcelona.

BRUMFIEL, E. y T. EARLE, 1987. Introduction. En Specialization, exchange, and complex societies, E. Brumfiel y T. Earle (Eds.), pp. 1-10. Cambridge University Press, Cambridge.
CASANOVA, E., 1958. El Pucara y su restauración. En Tilcara, pp. 29-45. Asociación Amigos de Tilcara, Tilcara.

CIGLIANO, E., 1973. Las ruinas arqueológicas. En Tastil, una ciudad prehispánica argentina, E. Cigliano (Ed.), pp. 65-120. Ediciones Cabargón, Buenos Aires.

CIGLIANO, E. y H. CALANDRA, 1973. Cerámica. En Tastil, una ciudad prehispánica argentina, E. Cigliano (Ed.), pp. 121-162. Ediciones Cabargón, Buenos Aires.

CIGLIANO, E. y R. RAFFINO, 1973. Tastil: Un modelo cultural de adaptación, función y desarrollo de una sociedad urbana prehistórica. Relaciones de la Sociedad Argentina de Antropología N. S. 6: 159-185.

CORNELL, P., 1993. Early centers and the household. A theoretical and methodological study on Latin American cases. GOTARC Series B:3, Göteborg Universitet, Göteborg.

CORNELL, P. y F. FAHLANDER, 2002. Microarchaeology, materiality and social practice. Current Swedish Archaeology 10: 21-38.

CORNELL, P. y P. STENBORG, 2001. Unit 12. En Investigations at Pichao. Introduction to studies in the Santa María Valley, Northwestern Argentina, L. Bengtsson, P. Cornell, N. Johansson y S. Sjödin (Eds.), pp. 47-66. BAR 978, Oxford.

CREMONTE, M. B., 1992. Algo más sobre el Pucara de Tilcara. Cuadernos de la Facultad de Humanidades y Ciencias Sociales 3: 35-52.

D'ALTROY,T.,A. M.LORANDI, V. WILLIAMS, M. CALDERARI, C. HASTORF, E. DEMARRAIS y M. HAGSTRUM, 2000. Inka rule in the Northern Calchaquí Valley, Argentina. Journal of Field Archaeology 27: 1-26.

DEMARRAIS, E., 1997. Materialization, ideology and power: The development of centralized authority among pre-Hispanic polities of the Calchaquí Valley, Argentina. Ph. D. Dissertation, University of California, Los Angeles.

2001. La arqueología del norte del valle Calchaquí. En Historia prehispánica argentina, vol 1, E. Berberián y A. Nielsen (Eds.), pp. 289-346. Editorial Brujas, Córdoba.

DIAZ, P. P., 1978-1980 Ms. Diario de la excavación realizada en el sitio Tero SSalCac 14. Informe depositado en el Museo Arqueológico de Cachi, Cachi.

DIP, S., 2001. Arquitectura y uso del espacio dentro del sitio Ojo de Agua, Casabindo. Actas del XIII Congreso Nacional de Arqueología Argentina, vol. 1, pp. 417-428. Córdoba.

FRIED, M., 1967. The evolution of political society. Random House, Nueva York.

GARAY, M., 1998. El Pucara de Volcán, historia ocupacional y patrón de instalación. En Los desarrollos locales y sus territorios. Arqueología del N.O.A. y sur de Bolivia, M. B. Cremonte (Ed.), pp. 131-154, Universidad Nacional de Jujuy, San Salvador de Jujuy.

GIDDENS, A., 1995. La constitución de la sociedad. Bases para la teoría de la estructuración. Amorrortu Editores, Buenos Aires. 
GIFFORD, C., 2003. Local matters: Encountering the imperial inkas in the South Andes. Ph. D. Dissertation, Columbia University, Nueva York.

GONZALEZ, A. R. y P. P. DIAZ, 1992. Notas arqueológicas sobre la "Casa Morada", La Paya, provincia de Salta. Estudios de Arqueología 5: 9-61.

GONZALEZ, L. R., 1997. Cuerpos ardientes. Interacción surandina y tecnología metalúrgica. Estudios Atacameños 14: $189-210$.

GONZALEZ, L. R. y P. PELAEZ, 1999. De ricos y famosos. Bienes metálicos en las sociedades prehispánicas tardías del Noroeste Argentino. Actas del XII Congreso Nacional de Arqueología Argentina, vol. 2, pp. 221-232. La Plata.

HAYDEN, D., 1997. Urban landscape history: The sense of place and the politics of space. En Understanding ordinary landscapes, P. Groth y T. Bressi (Eds.), pp. 111-133. Yale University Press, New Haven y Londres.

HODDER, I., 1994. Interpretación en arqueología. Editorial Crítica ( $2^{\text {a }}$ edición), Barcelona.

INGOLD, T., 2000. The perception of environment. Essays on livelihood, dwelling and skill. Routledge, Londres y Nueva York.

JOHANSSON, N., 2001. The excavation of the cemeteries 1991-1992. En Investigations at Pichao. Introduction to studies in the Santa María Valley, Northwestern Argentina, L. Bengtsson, P. Cornell, N. Johansson y S. Sjödin (Eds.), pp. 119-148. BAR 978, Oxford.

JOHNSTON, R., 1998. Approaches to the perception of landscape. Philosophy, theory, methodology. Archaeological Dialogues 5 (1): 54-68.

KRAPOVICKAS, P., 1969. Instalación aborigen en "Pucara de Yacoraite" (provincia de Jujuy, República Argentina). Etnía 10: 8-12.

LAZZARI, M., 1999. Distancia, espacio y negociaciones tensas: El intercambio de objetos en arqueología. En Sed non satiata. Teoría social en la arqueología latinoamericana contemporánea, A. Zarankin y F. Acuto (Eds.), pp. 117-151. Ediciones del Tridente, Buenos Aires.

LEFEBVRE, H., 1991. The production of space. Blackwell, Oxford.

LEIBOWICZ, I., 2006. Dominación inca, ideología y espacio en La Huerta de Huacalera, provincia de Jujuy, Argentina. Tesis de Licenciatura, Facultad de Filosofía y Letras, Universidad de Buenos Aires, Buenos Aires.

LORANDI, A. M., 1988. Los diaguitas y el Tawantinsuyu. Una hipótesis de conflicto. En La frontera del Estado inca, T. Dillehay y P. Netherly (Eds.), pp. 215-234. BAR 442, Oxford.

2003. Los valles calchaquíes revisitados. Anales Nueva Epoca 6: 273-285.
LORANDI, A. M. y R. BOIXADOS, 1987-1988. Etnohistoria de los valles calchaquíes en los siglos XVI y XVII. Runa XVII-XVIII: 263-419.

MADRAZO, G., 1969. Los sectores de edificación en el Pucara de Tilcara (provincia de Jujuy). Etnía 9: 21-27.

MCGUIRE, R. H., 1992. A marxist archaeology. Academic Press, Nueva York.

MILLER, D., 1987. Material culture and mass consumption. Basil Blackwell, Oxford.

NASTRI, J., 1997-1998. Patrones de asentamiento prehispánico tardíos en el suroeste del valle de Santa María (Noroeste Argentino). Relaciones de la Sociedad Argentina de Antropología 22-23: 247-270.

1999. Arquitectura, organización del espacio e instalaciones prehispánicas tardías en el valle de Santa María. Actas del XII Congreso Nacional de Arqueología Argentina vol. 3, pp. 321-326. La Plata.

NIELSEN, A., 1995. Architectural performance and the reproduction of social power. En Expanding archaeology, J. Skibo, W. Walker y A. Nielsen (Eds.), pp. 47-66. University of Utah Press, Salt Lake City.

_ 1996. Demografía y cambio social en la quebrada de Humahuaca (Jujuy, Argentina) 700-1535 DC. Relaciones de la Sociedad Argentina de Antropología 21: 307-354.

2001. Evolución social en la quebrada de Humahuaca (AD 700-1536). En Historia prehispánica argentina, vol. 1, E. Berberián y A. Nielsen (Eds.), pp. 171-264. Editorial Brujas, Córdoba.

2006. Plazas para los antepasados: Descentralización y poder corporativo en las formaciones políticas preincaicas de los Andes circumpuneños. Estudios Atacameños 31: 63-89.

NIELSEN, A. y W. WALKER, 1999. Conquista ritual y dominación política en el Tawantinsuyu. El caso de Los Amarillos (Jujuy, Argentina). En Sed non satiata. Teoría social en la arqueología latinoamericana contemporánea, A. Zarankin y F. Acuto (Eds.), pp. 153-69. Ediciones del Tridente, Buenos Aires.

NIELSEN, A., M. I. HERNANDEZ LLOSAS y C. RIVOLTA, 2004. Nuevas investigaciones arqueológicas en Juella (Jujuy, Argentina). Estudios Sociales del N.O.A. 7 (7): 93-116.

NUÑEZ REGUEIRO, V., 1974. Conceptos instrumentales y marco teórico en relación al análisis del desarrollo cultural del Noroeste Argentino. Revista del Instituto de Antropología V.

OTTONELLO, M., 1973. Instalación, economía y cambio cultural en el sitio tardío de Agua Caliente de Rachaite. Publicaciones de la Dirección de Antropología e Historia de Jujuy 1: 23-68.

OTTONELLO, M. y A. M. LORANDI, 1987. Introducción a la arqueología y etnología. Eudeba, Buenos Aires. 
PALMA, J. R., 1997-1998. Ceremonialismo mortuorio y registro arqueológico: Apuntes sobre complejidad social. Relaciones de la Sociedad Argentina de Antropología 22-23: 179-202.

1998. Curacas y señores: Una visión del la sociedad política prehispánica en la quebrada de Humahuaca. Instituto Interdisciplinario Tilcara, Universidad de Buenos Aires, Buenos Aires.

2000. Urbanismo y complejidad social en la región Humahuaca. Estudios Sociales del N.O.A. 4 (2): 31-57.

2003. La funebria de Campo Colorado, quebrada de Humahuaca (depto. de Tilcara, Jujuy). Relaciones de la Sociedad Argentina de Antropología 28: 61-74.

PARKER PEARSON, M., 2000. The archaeology of death and burial. Texas A \& M University Press, College Station.

PAUKETAT, T., 2000. The tragedy of commoners. En Agency in archaeology, M. A. Dobres y J. Robb (Eds.), pp. 113-129. Routledge, Londres y Nueva York.

2001. Practice and history in archaeology: An emerging paradigm. Anthropological Theory 1 (1): 73-98.

POTTEIGER, M. y J. PURINTON, 1998. Landscape narratives. J. Wiley \& Sons, Nueva York.

RAFFINO, R., 1972. Las sociedades agrícolas del Período Tardío en la quebrada del Toro (prov. de Salta). Revista del Museo de la Plata, Nueva Serie vol. VII, Antropología 45: 157-210.

-1988. Poblaciones indígenas de la Argentina. Editorial TEA, Buenos Aires.

RAFFINO, R. y R. ALVIS, 1993. Las ciudades incas en Argentina: Arqueología de La Huerta de Humahuaca. El sistema de poblamiento prehispánico. En Inka. Arqueología, historia y urbanismo del altiplano andino, R. Raffino (Ed.), pp. 37-76. Corregidor, Buenos Aires.

REYNOSO, A., 2003. Arqueoastronomía en Rincón Chico (Catamarca, Argentina). Monumentos del tiempo, monumentos de encuentro en el valle de Yocavil. Anales Nueva Epoca 6: 127-161.

RIVOLTA, C., 2007. Las categorías de poblados en la región Omaguaca: Una visión desde la organización social. En $\mathrm{La}$ vivienda, la comunidad y el territorio, A. Nielsen, C. Rivolta, P. Mercolli, M. Vásquez y V. Seldes (Eds.), pp. 143-162. Editorial Brujas, Córdoba.

ROSE, G., 1995. Place and identity: A sense of place. En A place in the world, D. Massey y P. Jess (Eds.), pp. 87-132. The Open University, Oxford.

SAHLINS, M., 1981. Historical metaphors and mythical realities. ASAO Special Publications 1. The University of Michigan Press, Ann Arbor.

SANCHEZ, S. y G. SICA, 1991. Algunas reflexiones acerca de los tilcaras. Avances en Arqueología 1: 82-99.

SCHAPOSCHNIK, A., 1996. Las jefaturas del Noroeste Argentino (siglos XVI-XVIII). En La integración surandina: Cinco siglos después, X. Albó, M. Aratia, J. Hidalgo, L. Núñez, A. Llagostera, M. Remy y B. Revesz (Eds.), pp. 189-204.
Universidad Católica del Norte y Centro de Estudios Regionales Andinos Bartolomé de las Casas, Estudios y Debates Regionales Andinos 91, Cusco.

SEMPE, C., 1999. La cultura Belén. Actas del XII Congreso Nacional de Arqueología Argentina, vol. 2, pp. 250-258. La Plata.

SERVICE, E., 1984. Los orígenes del Estado y la civilización. Alianza Universidad, Madrid.

SHANKS, M. y C. TILLEY, 1982. Ideology, symbolic power and ritual communication: A reinterpretation of Neolithic mortuary practices. En Symbolic and structural archaeology, I. Hodder (Ed.), pp. 129-154. Cambridge University Press, Cambridge.

-1987. Social theory and archaeology. Polity Press, Oxford.

SOJA, E., 1989. Postmodern geographies. The reassertion of space in critical social theory. Verso, Londres y Nueva York.

SJÖDIN, S., 2001. Clay pots and potters' work: Archaeology and ethnoarchaeology at Pichao. En Investigations at Pichao. Introduction to studies in the Santa María Valley, Northwestern Argentina, L. Bengtsson, P. Cornell, N. Johansson y S. Sjödin (Eds.), pp. 165-180. BAR 978, Oxford.

STENBORG, P., 2001. Holding back history. Issues of resistance and transformation in a post-contacts setting, Tucumán, Argentina ca. AD 1536-1660. Institutionen för Arkeologi, Göteborg Universitet, Göteborg.

TABOADA, C. y C. ANGIORAMA, 2003a. Posibilidades de un enfoque dinámico para el estudio de la arquitectura doméstica prehispánica. Un caso de aplicación en Los Amarillos (Jujuy). Relaciones de la Sociedad Argentina de Antropología 28: 101-116.

2003b. Buscando los indicadores arqueológicos de la unidad doméstica. Cuadernos de la Facultad de Humanidades y Ciencias Sociales 20: 393-407.

TARRAGO, M., 1977. La localidad arqueológica de Las Pailas, provincia de Salta, Argentina. Actas del VII Congreso Nacional de Arqueología Chilena, vol. 2, pp. 499-517. Altos de Vilches.

1987. Sociedad y sistema de asentamiento en Yocavil. Cuadernos del Instituto Nacional de Antropología 12: 179-196.

1992. Areas de actividad y formación del sitio de Tilcara. Cuadernos de la Facultad de Humanidades y Ciencias Sociales 3: 64-74.

1995. Desarrollo regional en Yocavil: Una estrategia de investigación. Hombre y Desierto 9: 225-235.

2000. Chakras y pukara. Desarrollos sociales tardíos. En Los pueblos originarios y la conquista. Nueva historia argentina, vol. 1, M. Tarragó (Ed.), pp. 257-300. Editorial Sudamericana, Buenos Aires.

TARRAGO, M. y L. R. GONZALEZ, 1996. Producción especializada y diferenciación social en el sur del valle de Yocavil. Anales de Arqueología y Etnología 50-51: 85-108. 
TARRAGO, M. y J. NASTRI, 1999. Dimensiones de la complejidad santamariana. Actas del XII Congreso Nacional de Arqueología Argentina, vol. 2, pp. 259-264. La Plata.

TARTUSI, M. y V. NUÑEZ REGUEIRO, 2001. Excavación de la unidad 6 del sector I del sitio STucTav 5 (El Pichao). En Investigations at Pichao. Introduction to studies in the Santa María Valley, Northwestern Argentina, L. Bengtsson, P. Cornell, N. Johansson y S. Sjödin (Eds.), pp. 85-100. BAR 978, Oxford.

THOMAS, J., 1996. Time, culture and identity. Routledge, Londres.

2001. Archaeologies of place and landscapes. En Archaeological theory today, I. Hodder (Ed.), pp. 165-186. Polity Press, Cambridge.
VAQUER, J. M., 2006 Ms. Análisis de planos como primera etapa en un proyecto de investigación. Un ejemplo de Cruz Vinto (Norte de Lípez, Bolivia) durante el Período de Desarrollos Regionales Tardío (ca. 1200-1430 AD). Ponencia presentada en las VII Jornadas de Jóvenes Investigadores en Ciencias Antropológicas, Instituto Nacional de Antropología y Pensamiento Latinoamericano, Buenos Aires.

WARNIER, J. P., 2001. A praxeological approach to subjectivation in a material world. Journal of Material Culture 6 (1): 5-24.

WILLIAMS, V., 2003. Nuevos datos sobre la prehistoria local en la quebrada de Tolombón. Provincia de Salta, Argentina. Anales Nueva Epoca 6: 163-209. 
